\title{
Winter Arctic sea ice thickness from ICESat-2: upgrades to freeboard and snow loading estimates and an assessment of the first three winters of data collection
}

\author{
Alek A. Petty ${ }^{1,2}$, Nicole Keeney ${ }^{1,2}$, Alex Cabaj ${ }^{3}$, Paul Kushner ${ }^{3}$, Marco Bagnardi ${ }^{1,4}$ \\ $5{ }^{1}$ Cryospheric Sciences Laboratory, NASA Goddard Space Flight Center, Greenbelt, MD, USA. \\ ${ }^{2}$ Earth System Science Interdisciplinary Center, University of Maryland, College Park, MD, USA. \\ ${ }^{3}$ University of Toronto, Toronto, Canada. \\ ${ }^{4}$ ADNET Systems Inc., Bethesda, MD, USA.
}

10 Correspondence to: Alek A. Petty (alek.a.petty@nasa.gov)

\begin{abstract}
Reliable basin-scale estimates of sea ice thickness are urgently needed to improve our understanding of recent changes and future projections of polar climate. Data collected by NASA's ICESat-2 mission have provided new, high-resolution, 15 estimates of sea ice freeboard across both hemispheres since data collection started in October 2018. These data have been used in recent work to produce estimates of winter Arctic sea ice thickness using snow loading estimates from the NASA Eulerian Snow On Sea Ice Model (NESOSIM). Here we provide an impact assessment of upgrades to both the ICESat-2 freeboard data (ATL10) and NESOSIM snow loading on estimates of winter Arctic sea ice thickness. Misclassified leads were removed from the freeboard algorithm in the third release (rel003) of ICESat-2 freeboard data, which increased

20 freeboards in January and April 2019, and increased the fraction of low freeboards in November 2018, compared to rel002. These changes improved comparisons of sea ice thickness (lower mean biases and standard deviations, higher correlations) with monthly gridded thickness estimates produced from ESA's CryoSat-2 (using the same input snow and ice density assumptions). Later releases (rel004 and rel005) of ICESat-2 ATL10 freeboards result in less significant changes in the freeboard distributions and thus thickness. The latest version of NESOSIM (version 1.1), forced by CloudSat-scaled ERA5 snowfall, has been re-calibrated using snow depth estimates obtained by NASA's Operation IceBridge airborne mission. The upgrade from NESOSIM v1.0 to v1.1 results in only small changes in snow depth which have a less significant impact on thickness compared to the rel002 to rel003 freeboard changes. Finally, we present our updated monthly gridded winter Arctic sea ice thickness dataset and highlight key changes over the past three winter seasons of data collection (November 2018 - April 2021). Strong differences in total winter Arctic thickness across the three winters are observed, linked to clear differences in the multiyear ice thickness at the start of each winter. Interannual changes in snow depth provide significant impacts on our thickness results on regional and seasonal scales. Our analysis of recent winter Arctic sea ice thickness variability is provided online in a novel Jupyter Book format to increase transparency and user engagement with our derived gridded monthly thickness dataset.
\end{abstract}




\section{Introduction}

NASA's Ice, Cloud, and Land Elevation Satellite-2 (ICESat-2) is providing significant advances in our ability to monitor Earth's fast-changing sea ice cover. The Advanced Topographic Laser Altimeter System (ATLAS) onboard ICESat-2 measures surface elevation at high resolution (individual laser footprints of $\sim 11 \mathrm{~m}$, Magruder et al., 2020) and high precision ( $<2 \mathrm{~cm}$ over sea ice flat surfaces, Kwok et al., 2019a), with dense along-track sampling (70 cm along-track from the $10 \mathrm{kHz}$ pulse repetition rate, Neumann et al., 2019). ATLAS was designed in part to obtain accurate and routine estimates of sea ice freeboard, the vertical extension of sea ice above local sea level, across the polar oceans (Markus et al., 2017). Sea ice freeboard can typically range from millimeters to tens of centimeters depending on the region or season profiled. ICESat-2 benefits from extensive polar coverage (profiling up to 88 degrees N/S, monthly sub-cycle) and has collected year-round data with minimal downtime since production started in October 2018. ICESat-2 sea ice height and freeboard data are provided in the official ATL07 (Kwok et al., 2021a) and ATL10 (Kwok et al., 2021b) products respectively. The first winter season of ICESat-2 Arctic Ocean sea ice freeboards (ATL10) was presented in Kwok et al., (2019b), highlighting the regional and seasonal freeboard distributions obtained by ICESat-2.

Validation of the ATL07 and ATL10 products is on-going. ATL07 sea ice heights showed very strong agreement (0 $\mathrm{cm}$ mean differences, correlation coefficients of 0.97 to 0.98 ) with coincident airborne data collected by NASA's Operation

50 IceBridge north of Greenland and the Canadian Archipelago in spring 2019 (Kwok et al., 2019a). The freeboard agreement was more modest (mean differences of 0 to $4 \mathrm{~cm}$ ), although the comparisons were hindered by the lack of available leads to reliably determine a local sea surface in either product. Additional analysis of the ATL07/10 surface classification scheme using imagery collected by the Copernicus Sentinel-2 mission, provided evidence of high skill in lead classification (Petty et al., 2021), a key part of the freeboard determination procedure. However, both the spring 2019 OIB Arctic campaign

55 comparisons (Kwok et al., 2021d) and Sentinel-2 imagery assessments (Petty et al., 2021) highlighted errors in the 'dark lead' classification in ATL07/10. Briefly, it was hypothesized that low/optically thin clouds in these regions attenuate the photon rate around these segments due to increased atmospheric scattering, tricking the empirical threshold-based classification algorithm into characterizing height segments over sea ice as dark leads. High photon rate specular leads are now the only lead types used to derive sea surface and thus freeboard in the Release 003 and subsequent sea ice products

60 (Release 005 at the time of writing) while a possible filter for the dark-lead segments is developed and tested. The impact of this change was an increase in freeboard in ATL10 of 0 to $3 \mathrm{~cm}$ depending on the season/region analyzed, as well as a decrease in coverage due to the reduction in sea surface tie-points (Kwok et al., 2021d).

Measurements of sea ice freeboard are typically collected as a means of estimating sea ice thickness (see schematic in Figure 1). This is conventionally achieved by combining freeboard measurements with ancillary estimates of snow 65 loading (snow depth and density), sea ice density and an assumption of hydrostatic equilibrium (e.g. Giles et al., 2007; Kwok and Cunningham, 2008; Laxon et al., 2013; Kwok, 2018). Sea ice thickness was estimated from Release 002 ATL10 freeboards using external snow loading estimates from the NASA Eulerian Snow on Sea Ice Model (NESOSIM) v1.0 and 
modified versions of the Warren climatology (Petty et al., 2020, P2020). The Feb/March 2019 ICESat-2 thicknesses were $\sim 10 \mathrm{~cm}$ thinner than Feb/Mar 2008 ICESat thickness estimates, alluding to a possible decline in end-of-winter Arctic sea ice thickness over this 11-year period. However, the P2020 thickness estimates were also significantly thinner than those produced using radar freeboard measurements from ESA's CryoSat-2 using the same input assumptions (tens of $\mathrm{cm}$ biases depending on the month and product analysed). Significant biases still exist in satellite-derived estimates of sea ice thickness, even those based on the same satellite sensor (e.g. radar altimetry data from ESA's CryoSat-2 mission, Sallila et al., 2019; Petty et al., 2020) which have limited their utility to-date, e.g. for constraining or calibrating polar climate

75 projections (e.g. SIMIP Community, 2020).

The thickness results presented in P2020 used NESOSIM v1.0 snow loading forced by ECMWF ERA-Interim (ERA-I) snowfall (Dee et al., 2011). However, ERA-I production ended in August 2019 and was superseded by ERA5 (Hersbach et al., 2020). While ERA5 total precipitation is similar to ERA-I over the Arctic Ocean (Wang et al., 2019; Barrett et al., 2020), ERA5 produces relatively more snowfall (and thus less rainfall) compared to ERA-I, especially in the Atlantic sector of the Arctic (Wang et al., 2019). Additional developments and calibration of NESOSIM have been carried out to upgrade NESOSIM (v1.0 to v1.1) and extend the derived ice thickness product beyond the first winter season (2018/2019) presented in P2020 which we present here.

The significant changes in ATL10 freeboards and the availability of updated NESOSIM snow loading warrants an updated winter Arctic sea ice thickness assessment. ATL10 and NESOSIM v1.1 output are now also available from fall 2018 through to spring 2021, providing three winter seasons of data to assess. The main objectives of this paper are to: (i) highlight upgrades to the ICESat-2 ATL10 freeboard product and NESOSIM v1.1 snow loading and assess their impact on winter Arctic sea ice thickness; (ii) carry out updated comparisons against CryoSat-2 derived thickness estimates; and (iii) assess monthly gridded thickness data from the past three winter seasons across the entire Arctic Ocean. The monthly gridded thickness analysis is also available online in a Jupyter Book format (https://nicolekeeney.com/icesat2-book) to increase transparency and user engagement in our analysis of these data.

\section{Input data and upgrades}

\subsection{ICESat-2 ATL10 freeboards}

We use the ICESat-2 ATL10 sea ice freeboard product (currently at Release 005, rel005), which is disseminated through the National Snow and Ice Data Center (NSIDC) (Kwok et al., 2021a). ATL10 is the end result of a series of algorithms that convert the primary geolocated photon product (ATL03, Neumann et al., 2019), to sea ice height and type (ATL07, Kwok et al., 2021a), and then sea surface height and freeboard (ATL10, Kwok et al., 2021b). Briefly, the ATL07 algorithm subtracts a mean sea surface and time-varying ocean tide and inverted barometer corrections from ATL03, then aggregates and windows 150 photons around this corrected surface along each beam independently. ATL07 then extracts a best-guess Gaussian height distribution (convolved with the expected system response) to the photon height histogram to determine a 
single 'segment' height and various metrics summarizing the goodness of fit and radiometry (e.g., photon rate) of each segment. This photon aggregation results in data with variable segment lengths of, on average, $\sim 15 \mathrm{~m}$ for the strong beams and $\sim 60 \mathrm{~m}$ for the weak beams (Kwok et al., 2019b). The spatial resolution of the individual segments can be estimated by adding the individual laser footprint size of $\sim 11 \mathrm{~m}$ (Magruder et al., 2020) to the segment length, i.e., a mean of $\sim 25 \mathrm{~m}$ for the strong beams and $70 \mathrm{~m}$ for the weak beams. An empirically based decision-tree algorithm is used to discriminate the height segments as either sea ice or sea surface/lead (Kwok et al., 2016). More details of the surface classification scheme are available in Kwok et al., (2021d) and Petty et al., (2021), while the complete processing methodology is available in the Algorithm Theoretical Basis Document (ATBD) for sea ice products (Kwok et al., 2021c).

ATL10 converts adjacent sea surface segments into lead groups (to reduce noise in the lead height estimate) and then averages these into $10 \mathrm{~km}$ along-track reference sea surface height estimates along each beam. Sea ice freeboard is calculated as the difference between the individual ice height segments and the local sea surface height, independently for each beam. The ICESat-2 beams are arranged in 'strong' and 'weak' beam pairs with each beam pair separated by $\sim 3.3$ kilometers in the across-track direction and the strong/weak beams separated by $\sim 90 \mathrm{~m}$ across-track and $\sim 2.5 \mathrm{~km}$ alongtrack. The weak beams are around 4 times lower energy (lower photon rate) than the strong beams. In this study we utilize only the strong beams to ensure the highest possible data quality.

\subsubsection{ATL10 upgrades}

The ICESat-2 sea ice products are continuously being updated as new assessments on the data are undertaken. All ICESat-2 products currently follow the same nominal release schedule ( $\sim 6-12$ months), so release updates are not necessarily based on the significance of the changes or improvements made to the given product. All new release data are processed and released from the start of the mission (October $\left.14^{\text {th }}, 2018\right)$ onwards, until the production of a new release begins. The sea ice thickness results presented in P2020 utilized re1002 ATL10 data, and differences with thickness estimates produced using rel001 ATL10 were noted to be negligible. As discussed earlier, in rel003 ATL10 (and subsequent releases), dark leads have been removed as possible sea surface height segments, since false positive classifications were found in the presence of clouds, resulting in 0-3 cm freeboard changes at basin-scales and some loss of coverage, especially within the more consolidated central Arctic ice pack (Kwok et al., 2021d). This is arguably the biggest change in the ICESat-2 sea ice products to-date. The rel003 ATL10 data also included a relaxing of the height/freeboard quality flag (from 3 to 4), which means height segments with a poorer fit (generally segments from ridges with a more variable and complex height profile) are now included to increase retrieval counts over ridged ice regimes.

In rel004, most of the updates involved changes related to the treatment of the solid earth tides (a transition of

130 ATL07 into a tide-free system to be consistent with ATL03). This caused a significant change in the magnitude of the heights reported in ATL07 and ATL10, but as freeboard is a relative measurement, this was not expected to impact the reported freeboards. In re1005 ATL10, the only changes relevant to freeboard determination include improved calculation of the $10 \mathrm{~km}$ reference surface location to the centre of each section (effectively a bug fix). The rel005 data now also includes 
data from previously held granules where known satellite calibration scans were occurring somewhere along the granule. New automated pointing angle and calibration scan filters were introduced in rel005 to ensure only data within each granule experiencing degraded performance are filtered out, instead of withholding entire data granules. Most other developments in rel003 to rel005 ATL10 can be categorized as minor bug fixes and are listed in the ATBD change log (available since rel004). It should also be noted that every new release of ATL07/10 has coincided with a new ATL03 release, meaning ATL07/10 release upgrades also reflect upgrades to the underlying ATL03 photon heights (e.g., improvements in geolocation).

In the Supplementary Information (Figure S1) we provide an assessment of the coverage change from rel002 to rel005 by counting the number of $10 \mathrm{~km}$ reference sea surface points available across the 4 releases from all data collected by the strong beams between November 2018 and April 2019. The analysis provides further evidence of the decline in coverage between rel002 and rel003. The rel003 to rel005 coverage differences are sporadic and linked mainly to the inclusion of calibration scan data granules. Calibration scans occur mainly over lower latitudes but can occasionally extend over the Arctic ice pack - data during these scans are generally considered degraded i.e., heights with sub-nominal geolocation quality. Automated calibration scan filtering was introduced in rel005 to exclude these data more reliably and ensure only the highest quality height returns are utilized. In Figure S2 we provide a beam coverage assessment over the same time period using rel005 data only, highlighting the consistently higher coverage provided by the strong beams compared to the weak beams (in this first winter of data collection), and especially the middle strong beam.

\subsection{NESOSIM}

We use snow depth and density estimates from the NASA Eulerian Snow On Sea Ice Model (NESOSIM) (Petty et al., 2018a, P2018) which is publicly available on GitHub (https://github.com/akpetty/NESOSIM). NESOSIM was developed primarily in preparation for the launch of ICESat-2, to enable timely production of snow depth and density estimates for seaice thickness retrievals using a simple snow accumulation model framework. NESOSIM includes two vertical snow layers and several simple parameterizations (accumulation, wind packing, advection-divergence, blowing snow loss) to represent the expected primary sources and sinks of snow on Arctic sea ice during the accumulation season. Summer melt processes are currently neglected, so the model is typically run between September and the end of April. NESOSIM v1.0 was first presented in P2018 and the output using this v1.0 framework was used in P2020 to produce snow loading needed to convert

160 ATL10 freeboards (rel002) to sea ice thickness from October 2018 to April 2019. The NESOSIM v1.0 output used in P2020 was forced with snowfall, winds and near-surface air temperature (to scale the initial snow conditions) from ERA-I (Dee et al., 2011), sea ice concentrations from the NASA Climate Data Record (CDR) version 3 (Meier et al., 2017), and ice drifts from the European Organization for the Exploitation of Meteorological Satellites (EUMETSAT) Ocean and Sea Ice Satellite Application Facility (OSI SAF) (Lavergne et al., 2010) which were all regridded to a $100 \mathrm{~km}$ x $100 \mathrm{~km}$ Arctic Ocean domain. 


\subsubsection{NESOSIM upgrades}

Here we describe recent upgrades made to NESOSIM which has been tagged as a new version 1.1 (v1.1) code release (https://github.com/akpetty/NESOSIM/releases/tag/v1.1, archived at https://doi.org/10.5281/zenodo.4448356). Key updates in NESOSIM v1.1 include: CloudSat snowfall scaling (described more below, Cabaj et al., 2020), a new wind-atmosphere blowing snow loss term, an extended Arctic domain to cover the full extent of the Arctic peripheral seas, an improved smoothing filter to reduce noise in the dynamic snow budget terms, an upgrade to Python 3, and various minor bug fixes. Much of the NESOSIM v1.1 development was motivated by the need to recalibrate NESOSIM using ERA5 forcings (Hersbach et al., 2020), now that ERA5 has succeeded ERA-I (ERA-I data production ended in August 2019) and given reports of increased ERA5 snowfall compared to ERA-Interim (Wang et al., 2019; Cabaj et al., 2020). ERA5 is thought to offer improvements over ERA-I related to improved cloud representation, an updated assimilation scheme and higher spatial resolution (Hersbach et al., 2020). Regardless, whether ERA5 exhibits a high snowfall bias over the Arctic or ERA-I a low bias is still uncertain and likely regionally dependant. Cabaj et al., (2020) used snowfall estimates from CloudSat to calibrate several reanalyses snowfall estimates, including ERA5, within the NESOSIM framework - reducing the spread in snowfall from the chosen reanalyses, although not significantly changing the magnitude of the ERA5 snowfall in the North Atlantic region, where winter snowfall rates are highest overall. On average, ERA5 reports more snowfall over the Arctic basin than what is observed by CloudSat measurements, so the scaling tends to slightly decrease the overall magnitude of the snowfall and the resulting snow depth in NESOSIM (Cabaj et al. 2020). The CloudSat-reanalysis scaling coefficients are now included in the NESOSIM v1.1 code repository.

The other significant code development was the introduction of a new blowing snow loss term. The parameterization of blowing snow lost to leads in NESOSIM v1.0 (Eq. 10 in P2018) has been challenged due to uncertainties around how much snow might be lost to leads under windy conditions, rather than sublimated (lost to the atmosphere) or transported either within or to adjacent grid-cells (Liston et al., 2020). Motivated by this, we introduced an additional blowing snow loss to the atmosphere term, which is a similar function of wind speed and snow in the top 'new' snow layer to the loss-to-leads term, but is not also a function of sea ice concentration:

190

$\Delta h_{s}{ }^{b s_{-} a}=\gamma \beta T_{d} U h_{s}$ for $U>\omega[1]$

where $h_{s}$ is the snow depth in the top 'new' snow layer, $U$ is the wind speed, $T_{d}$ is the number of seconds in the daily timestep, $\omega$ is the wind action threshold, $\beta$ is the blowing snow loss coefficient and $\gamma$ is a new (unitless) atmosphere snow loss coefficient. This parameterization, which provides a simple mechanism for increasing snow loss under given atmospheric conditions independent of sea ice conditions, requires calibration of an additional free parameter, $\gamma$.

Additionally, NESOSIM v1.1 was forced with daily sea ice concentrations from the NASA Climate Data Record (CDR) version 3 (Meier et al., 2017), daily ice drifts from both the NSIDC Polar Pathfinder version 4 dataset (Tschudi et al., 
https://doi.org/10.5194/tc-2022-39

Preprint. Discussion started: 16 February 2022

(c) Author(s) 2022. CC BY 4.0 License.

\section{(c) $\underset{\mathrm{BY}}{\mathrm{BV}}$}

2019) from 1980 to April 2019 and daily drifts from the European Organization for the Exploitation of Meteorological Satellites (EUMETSAT) Ocean and Sea Ice Satellite Application Facility (OSI SAF) global low resolution ice drift dataset (Lavergne et al., 2010) from September 2019 to April 2021 due to contrasting data availability. As noted in P2018, the impact on snow depth from ice drift forcing is generally second order to snowfall, although this can have first-order impacts at more regional scales. All forcings were regridded to our updated $100 \mathrm{~km}$ x $100 \mathrm{~km}$ North Polar Stereographic (EPSG: 3413, https://epsg.io/3413) Arctic Ocean model domain.

We recalibrated NESOSIM v1.1 considering the new forcings and model changes described above, by targeting estimates of spring Arctic snow depths derived from Snow Radar data collected during NASA's Operation IceBridge as used in P2018: the snow radar layer detection (SRLD) product (Koenig et al., 2016), the NASA Goddard Space Flight Center (GSFC) empirical threshold based product (Kurtz et al., 2013) and the Jet Propulsion Laboratory (JPL) product (Kwok et al., 2017). Our approach differs from the calibration approach used in P2018, which calibrated NESOSIM v1.0 against Soviet Station drifting station data collected in the 1980s (Warren et al., 1999) then assessed these results against OIB-derived snow depths. Here we choose instead to recalibrate NESOSIM v.1.1 against the spring OIB snow depth data from 2010 to 2015 to provide a more reliable snow depth representation focussed on our contemporary period of interest. We retain, however, the density values for the new 'top' and old 'bottom' layer snow (Table 1) which were derived from the Soviet Station calibration effort.

As noted in P2018 and presented in (Kwok et al., 2017), there is a large spread between the available OIB snow depth products due to various challenges in interpreting Snow Radar data. To account for this large inter-product uncertainty, we develop a 'consensus' gridded OIB spring snow depth product. We take all raw ( $\sim 7 \mathrm{~m}$ along-track resolution) snow depth measurements from the three snow depth retrieval algorithms for a given day, bin them to the $100 \mathrm{~km} \times 100 \mathrm{~km}$ NESOSIM v1.1 Arctic Ocean model domain using a simple binning procedure (average of all snow depths in the given grid-cell in each day), then take the median snow depth value at each daily grid-cell across the three OIB products. Quick-Look (QL) snow depths are available for the more recent years (2012 to 2019), using the GSFC waveform fitting approach (https://nsidc.org/data/NSIDC-0708/versions/1). However, it was noted in Kwok et al., (2017) that these estimates tend to exhibit a low bias compared to the other OIB products. A low bias in the GSFC QL product was also shown based on in-situ measurements collected in March 2014 (King et al., 2015). These biases were confirmed in our own analysis comparing our consensus OIB snow depths with the GSFC QL product (2013-2015), showing mean biases of $\sim 6 \mathrm{~cm}$ (QL thinner than our consensus product, see Supplementary Figure S4), motivating us to exclude these from our model calibration efforts here.

We heuristically calibrated NESOSIM v1.1 using the daily OIB consensus gridded snow depths with the aim of removing the mean bias relative to OIB when using the default NESOSIM v1.0 parameter settings (Figure 2a). Current work is exploring more automated calibration approaches (Cabaj et al., 2021), but here we were able to find a solution that 230 reduced the mean bias to $0 \mathrm{~cm}$ by halving the blowing snow coefficient, tuning the new atmosphere snow loss coefficient, $\gamma$, and extending the model initialization date to September 1 (instead of August 15) as shown in Figure 2b. In the absence of contemporary ground-truth data, we view the initial conditions (either their distribution or the representative start date) as 
https://doi.org/10.5194/tc-2022-39

Preprint. Discussion started: 16 February 2022

(c) Author(s) 2022. CC BY 4.0 License.

\section{(c) (i)}

another tuning parameter, within reason. For example, the SnowModel-LG framework presented in Liston et al., (2020) instead initializes with zero snow on August 1st of each year, assuming the snowpack melts out completely each summer based on interpretation of the Warren snow climatology (Warren et al., 1999, W99). As NESOSIM includes no snow melt terms, we prefer instead to initialize later in the year (Sep 1st) and prescribe an expected end of August snow depth. NESOSIM v1.1 was run from 1980 to 2021 and is expected to be updated in future years to enable continued thickness processing from ICESat-2. The output from this v1.1 model framework from 1980-2021 has been archived on Zenodo (https://doi.org/10.5281/zenodo.5164314). The NESOSIM v1.0 output from P2018 was originally released from 2000 to 2015 only but was extended for the 2018/2019 winter to produce snow depths used in the initial P2020 ICESat-2 sea ice thickness processing.

Figure 3 shows a time-series comparison of the October and April mean snow depths from NESOSIM v1.0 and v1.1 within an Inner Arctic Ocean domain (Central Arctic, Beaufort Sea, Chukchi Sea, Laptev Sea, Kara Sea). Our Inner Arctic Ocean domain was generated using a new National Snow and Ice Data Center (NSIDC) regional mask of the Arctic Ocean courtesy W. Meier and S. Stewart, see Supplementary Information Figure S3. NESOSIM v1.1 shows good agreement with v1.0 in terms of the October and April mean snow depth and patterns of interannual variability. Differences between the two releases are $<5 \mathrm{~cm}$ and often near zero. The longer record of NESOSIM v1.1 output is strongly suggestive of a longterm declining trend in snow depth and near-record low snow depths in recent years (i.e., the ICESat-2 period 2018-2021). To place the ICESat-2 period results in broader context, Figure 3 shows the monthly mean NESOSIM v1.1 snow depth distributions as violin plots, with the recent ICESat-2 years overlaid. During the initial months of winter (September/October), recent years show similar or deeper than average snow, while the middle/end-of-winter months (November to April) show thinner than average snow. The 2019-2020 and 2020-2021 snow depths especially are at or near record low values across most of these months. A more detailed snow depth trend analysis is beyond the scope of this study.

Finally, planning is on-going to release a Quick Look ( 2-3-day latency) ATL10 sea ice freeboard product (the current public release latency of ATL10 is $\sim 2-3$ months). A Quick Look ATL07 product was recently made available on the NSIDC (https://nsidc.org/data/ATL07QL). Producing near-real time NESOSIM output to derive near-real time thickness estimates is challenging due to the reliance on various forcing datasets from different international groups released at different latencies, so we also produce and describe here the production of a contemporary NESOSIM-derived snow depth/density climatology towards the goal of near real-time thickness assessments with ICESat-2. We take the mean

NESOSIM snow depth and density value for each day of the year in each grid-cell averaged across the period September 1 , 2010, to April 30, 2020. These climatology results (averaged across the Inner Arctic Ocean domain, Figure S3) are also highlighted in Figure 3 and have also been archived on Zenodo (https://doi.org/10.5281/zenodo.5164314).

\subsection{ICESat-2 sea ice thickness data upgrades}

We use the same approach as in P2020 to generate estimates of winter Arctic sea ice thickness and an associated uncertainty estimate. Briefly, thickness is calculated assuming hydrostatic equilibrium and input estimates of sea ice density, snow depth 
and snow density. The coarse resolution $(\sim 100 \mathrm{~km})$ snow depth input estimate, primarily from NESOSIM, is redistributed to the high-resolution ( $\sim 30 \mathrm{~m}$ ) ATL10 freeboards using a piecewise functional fit obtained from snow depth and freeboard data collected by NASA's Operation IceBridge mission. Uncertainties are calculated by propagating errors through the hydrostatic equilibrium equation with contributions from random errors (estimates based on previous studies) and systematic errors (estimates based on the spread in applied input assumptions). Small differences in our thickness processing to that presented in P2020 include a bilinear interpolation scheme instead of nearest neighbour to assign NESOSIM data to the ATL10 freeboard segments. Nearest neighbour interpolation was originally used to reduce processing time but introduces unphysical step changes. We also fixed some minor bugs in the freeboard uncertainty calculation and have incorporated the new NSIDC regional mask of the Arctic Ocean (courtesy W. Meier and S. Stewart, NSIDC, see Supplementary Information Figure S3). As in P2020 we use daily estimates of ice type from the European Organization for the Exploitation of Meteorological Satellites (EUMETSAT) Ocean and Sea Ice Satellite Application Facility (OSI SAF, www.osi-saf.org) (Breivik et al., 2012) to classify each segment as either first-year ice (FYI) or multiyear ice (MYI). Ice type information is needed in-part to derive the modified Warren snow depth estimates (see Section 2.2.2. in P2020), so our approach is to assume all ice is MYI unless the OSI SAF product explicitly characterizes the segment as FYI. Thus, in September when OSI SAF does not provide any ice type estimate due to added uncertainties in the end-of-summer retrievals, we assume all our ATL10, and derived thickness data are MYI. The along-track data, both raw and $10 \mathrm{~km}$ means, are being made available through the NSIDC (IS2SITDAT4, link to be provided upon completion of peer review) and will be updated as new ATL10 data are released.

In producing the monthly gridded dataset, we use all three strong beams to increase coverage and lower expected uncertainties, compared to the single strong beam used in P2020. The use of all three strong beams was also motivated by the reduction in data coverage in rel003 (and onwards) ATL10 data processing (described in Section 2.1.1 and noted in Figure S1). Our gridding approach is slightly different from the official gridded ICESat-2 freeboard product (ATL20, https://nsidc.org/data/ATL20) as we bin all data within a given month for each grid-cell, as opposed to producing daily gridded composites then monthly gridded composites from the daily gridded data. Our monthly gridded data includes ancillary data variables representative of the mean day of the month for each grid-cell calculated as the mean date of the input ATL10 data, and the number of ATL10 freeboard segments used in the monthly grid-cells to enable sampling bias assessments. The monthly gridded data also includes monthly NOAA/NSIDC Version 4 Climate Data Record (CDR) sea ice concentrations (Meier et al., 2021), the new NSIDC regional mask of the Arctic Ocean (courtesy W. Meier and S. Stewart, NSIDC) and the OSI SAF ice type mask (sub-sampled by ICESat-2 then gridded monthly). The data are projected on to the

295 NSIDC North Polar stereographic grid (EPSG: 3411, https://epsg.io/3411) and binned onto a $25 \mathrm{~km}$ x $25 \mathrm{~km}$ grid.

To further mitigate some of the data gaps and spatial sampling biases, we now also generate smoothed and interpolated variables of freeboard, snow depth and thickness. Our approach is as follows: i) set monthly mean grid-cells to zero where the monthly CDR concentration is valid and less than $15 \%$, ii) apply linear interpolation using Delaunay triangulation (https://docs.scipy.org/doc/scipy/reference/generated/scipy.interpolate.LinearNDInterpolator.html) on all grid- 

in $\mathrm{x}$ and $\mathrm{y}$ directions; iv) mask all grid-cells greater than $50 \mathrm{~km}$ away from grid-cells containing data in the original monthly gridded dataset using a KDTree algorithm, v) mask interpolated/smoothed data where the monthly NOAA/NSIDC CDR concentration is $<50 \%$. We expect that future work will explore more sophisticated interpolation procedures and blending with other thickness datasets (discussed more in the summary).

The initial version of this monthly gridded dataset described in P2020 (no interpolated variables, no region mask or sea ice concentration data, based on rel004 ATL10) was made available through the NSIDC (IS2SITMOGR4 Version 1, https://nsidc.org/data/IS2SITMOGR4). An updated dataset using the updated rel005 ATL10 data and including the interpolated variables, updated NSIDC Arctic region mask and CDR sea ice concentrations shown in this study are being made available as a new version 2 (v2) release of the IS2SITMOGR4 dataset which we expect to keep updated along with the along-track product (IS2SITDAT4) as new ATL10 data are released.

\subsection{CryoSat-2 sea ice thickness estimates}

Following P2020 we compare our winter Arctic sea ice thickness estimates with those generated from the European Space Agency (ESA) CryoSat-2 mission from four different groups: NASA's Goddard Space Flight Center (GSFC, Kurtz and Harbeck, 2017), the Jet Propulsion Laboratory (JPL, Kwok and Cunningham, 2015), the Center for Polar Observation and Modelling (CPOM, Laxon et al., 2013; Tilling et al., 2018) and the Alfred Wegener Institute (AWI, Hendricks and Ricker, 2016). As the different products make different assumptions regarding snow loading and sea ice, for these comparisons we use the same snow loading assumptions in our ICESat-2 thickness processing to generate direct thickness comparisons (instead of the NESOSIM based thickness estimates). As in P2020 we re-grid the monthly gridded CS-2 estimates to the NSIDC $25 \mathrm{~km}$ x $25 \mathrm{~km}$ North Polar Stereographic grid using a simple nearest neighbor interpolation scheme and compare these with our gridded ICESat-2 sea ice thickness estimates that have been produced using the same snow loading and ice density assumptions as the given CS-2 product, as summarized in Table 2 in P2020 (e.g., modified versions of the Warren climatology snow loading). Note that in the CryoSat-2 comparisons we produce monthly gridded data using strong beam \#1 only to be consistent with the results shown in P2020.

Modified versions of the Warren snow depth climatology (mW99, Warren et al., 1999) were used by all four of these CryoSat-2 thickness products (it is worth noting that most of these groups are actively working on incorporating more sophisticated snow loading models). P2020 noted strong differences between NESOSIM v1.0 and mW99 (mW99, snow depths halved over first-year ice, see Supplementary Figures S2 to S4 in P2020). Generally, snow depths are similar over the thicker multiyear ice, but mW99 is thinner later in the year, due primarily to the reduced snow over first-year ice. Figure 3 shows the mean Inner Arctic Ocean snow depth from mW99 (snow depths halved using observed OSI SAF ice types from 3302010 to 2019), showing similar values to NESOSIM in October but thinner mW99 snow in April. Again, we use the same snow loading when producing comparison ICESat-2 thickness estimates, but it is worth noting that these thickness estimates will be different to our NESOSIM-derived thickness product due to these differences in snow. 
https://doi.org/10.5194/tc-2022-39

Preprint. Discussion started: 16 February 2022

(c) Author(s) 2022. CC BY 4.0 License.

(c) (i)

\subsection{PIOMAS sea ice thickness estimates}

In this study we additionally compare our gridded winter Arctic sea ice thickness estimates with those generated from the

Pan-Arctic Ice-Ocean Modeling and Assimilation System (PIOMAS, v2.1; Zhang \& Rothrock, 2003). PIOMAS is an iceocean model that generates estimates of sea ice thickness, constrained predominantly by the assimilation of sea ice concentration and sea surface temperature. PIOMAS data is commonly used in the sea ice community for longer-term assessments of Arctic sea ice thickness change. PIOMAS ice thicknesses estimates have been shown to exhibit differences on the order of tens of centimeters compared to satellite-derived estimates, although this depends strongly on the season and region analyzed (Schweiger et al., 2011; Zygmuntowska et al., 2014; Petty et al., 2018b).

\section{Results}

\subsection{ATL10 freeboards, NESOSIM snow loading and sea ice thickness distributions}

In Figure 4 we show probability distributions of winter Arctic sea ice freeboard calculated using rel002 (as used in P2020) through to rel005 ATL10 data. We show distributions from November 2018, January 2019, and April 2019 to assess differences during different regimes of winter Arctic sea ice (early, middle and late winter) for the first season of data collection. The distributions use data collected by strong beam \#1 only within an Inner Arctic Ocean domain (Central Arctic, Beaufort Sea, Chukchi Sea, Laptev Sea, Kara Sea). Note that in these distributions we show only positive values of freeboard (and later snow depth and thickness), while in the raw along-track IS2SITDAT4 dataset zero freeboards, typically from open water lead segments, are included also.

Figure 4 shows that the only notable change in freeboard distribution occurs between rel002 and rel003 - a freeboard decrease of $1.2 \mathrm{~cm}$ in November $2018(26.2 \mathrm{~cm}$ to $25.0 \mathrm{~cm})$, a $1.9 \mathrm{~cm}$ increase in January $2019(27.7 \mathrm{~cm}$ to 29.6 $\mathrm{cm}$ ) and a $3.4 \mathrm{~cm}$ increase in April 2019 (35.9 cm to $39.3 \mathrm{~cm})$. In contrast, the rel003 to rel005 freeboard distribution differences across these three months are small or negligible $(<0.4 \mathrm{~cm})$. Rel005 generally shows the highest freeboards from the four releases. As discussed earlier, this was largely expected due to the significant algorithm change in rel003 (Kwok et al., 2021d) and the lack of significant algorithm changes related to freeboard derivation in rel004 and rel005. The $1.2 \mathrm{~cm}$ mean freeboard reduction in November 2018 is due to a more significant primary freeboard mode and a less significant secondary peak in the rel003 to rel005 freeboard distributions, while January 2019 and April 2019 distributions exhibit a clear increase in the unimodal freeboard in rel003 onwards. Kwok et al., (2021d) analysed gridded freeboard distributions in January 2019, June 2019, October 2019 and found $3 \mathrm{~cm}, 1 \mathrm{~cm}$ and $2 \mathrm{~cm}$ increases respectively between rel002 and rel003, in-line with the differences observed here. As discussed in Section 2.1.1 and demonstrated in Figure S1, the different releases also include changes in coverage, especially between rel002 and rel003, which may influence these differences along with changes in the freeboard determination algorithm. 
Figure 4 (right column) also shows an analysis of the inter-beam differences across the three strong beams for the same time periods and Inner Arctic Ocean region for rel005 data only. The inter-beam differences are small $(<1 \mathrm{~cm})$, similar to the rel003-rel005 differences. Each strong beam is separated by $\sim 3 \mathrm{~km}$ across track, so more significant differences are expected at local scales, however an in-depth analysis of spatial length-scales is beyond the scope of this study. We instead note that at basin/monthly scales, the beams provide similar freeboard distributions despite the small differences in coverage (as discussed in Section 2.1.1 and highlighted in Figure S2), increasing our confidence in using all three beams to extend coverage across the Arctic.

Figure 5 shows the impact of three different NESOSIM frameworks (v1.0, v1.1 and v1.1clim) based on rel004 freeboards on the redistributed snow depths (these assessments were carried out during the period of rel004 availability). The piecewise redistribution of the coarse $100 \mathrm{~km}$ NESOSIM output to the high-resolution ATL10 data is summarized in Section 2.3 and presented in P2020. The difference in mean snow depth across the three months and NESOSIM frameworks is $<1.5$ $\mathrm{cm}$, with the biggest difference occurring in the November 2018, where the Nv1.1 redistributed snow depths are thicker than the Nv1.0 snow depths $(17.0 \mathrm{~cm}$ compared to $15.5 \mathrm{~cm})$ driven primarily by a small positive shift in the tail of the distribution. The January and April mean snow depths are similar across the NESOSIM frameworks, although slight differences in the distributions are observed, e.g., a thinner secondary snow depth peak in Nv1.1 compared to Nv1.0 $(\sim 22 \mathrm{~cm}$ compared to $\sim 26 \mathrm{~cm}$ ). The Nv1.1clim results are similar, although noteworthy for the more distinct secondary snow depth peak $(\sim 28-29 \mathrm{~cm})$ and thicker primary peak $(\sim 4-5 \mathrm{~cm}$ thicker) in the November 2018 and January 2019 distributions compared to the Nv1.0/Nv1.1 snow depths. All distributions capture the same general seasonal evolution (distributions and mean values) and show a similar unimodal snow depth distribution in April 2019.

Figure 5 (right column) shows the impact of the different NESOSIM frameworks on estimates of sea ice thickness. The difference in mean sea ice thickness across the three months and NESOSIM frameworks is greatest in November 2018: Nv1.1 thicknesses are $10 \mathrm{~cm}$ thinner than Nv1.0 while the Nv1.1clim thicknesses show a higher primary peak but longer tail.

385 The thickness differences across the three NESOSIM frameworks are $4 \mathrm{~cm}$ in January 2019 and $2 \mathrm{~cm}$ in April 2019. In general, the impact on thickness from the choice of NESOSIM framework (including the NESOSIM climatology) is less significant than the impact from rel002 to rel003 freeboard changes.

\subsection{Comparisons with CryoSat-2}

In Figure 6 we show comparison statistics (correlation coefficient, mean bias and standard deviation) of monthly gridded sea ice thickness estimates using both re1002 and rel003 ATL10 freeboards with those produced from ESA's CryoSat-2 using the same input assumptions, i.e., modified versions of the Warren climatology for snow loading (See Table 2 in P2020). As in P2020 we only use strong beam \#1 and mask all data below $0.25 \mathrm{~m}$ in both datasets and outside of an Inner Arctic Ocean domain before producing these comparisons.

In general, the agreement between ICESat-2 and CryoSat-2 using rel003 ATL10 freeboards is improved compared 395 to those based on re1002 ATL10 freeboards in terms of the correlation coefficient, mean bias and standard deviation across 
most months and products. In November 2018 the correlation coefficient increases from 0.66 - 0.77 (re1002 ATL10) to 0.80 0.88 (rel003 ATL10), the mean bias reduces from $0.35 \mathrm{~m}-0.65 \mathrm{~m}$ to $0.20 \mathrm{~m}-0.55 \mathrm{~m}$ and the standard deviation reduces from $0.60 \mathrm{~m}-0.79 \mathrm{~m}$ to $0.40 \mathrm{~m}-58 \mathrm{~m}$ across the four product comparisons. In January 2019 the correlation coefficient increases from 0.55 - 0.65 (rel002 ATL10) to 0.60 - 0.72 (rel003 ATL10), the mean bias reduces from $0.35 \mathrm{~m}-0.50 \mathrm{~m}$ to $0.05 \mathrm{~m}-0.22 \mathrm{~m}$ and the standard deviation reduces from $0.58 \mathrm{~m}-0.77 \mathrm{~m}$ to $0.50 \mathrm{~m}-0.62 \mathrm{~m}$. In April 2019 the correlation coefficient increases from 0.20 - 0.40 (rel002 ATL10) to 0.39 - 0.55 (rel003 ATL10), the mean bias reduces from $0.02 \mathrm{~m}-$ $0.35 \mathrm{~m}$ to $-0.30 \mathrm{~m}--0.05 \mathrm{~m}$ and the standard deviation reduces from $0.95 \mathrm{~m}-1.07 \mathrm{~m}$ to $0.68 \mathrm{~m}-0.80 \mathrm{~m}$. The statistics from all months between November 2018 and April 2019 are shown in Figure 6. More work is needed to better reconcile these datasets and assess sources of bias (as discussed more in the summary) but these results represent an encouraging initial development in terms of the ICESat-2 sea ice freeboard and thickness product development.

\subsection{Gridded Arctic sea ice thickness and comparisons over the last three winters.}

In Figure 7 we show an example output of our updated monthly gridded ICESat-2 winter Arctic sea ice thickness product (IS2SITMOGR4 version 2, v2) for April 2021 using the latest default thickness processing configuration (rel005 ATL10 and NESOSIM v1.1 snow loading). Spatial coverage is high across all months (not shown) despite the concerns expressed in

410 Kwok et al., (2021d) related to reduced lead/sea surface height segments and thus freeboard determination. This was partly mitigated by our use of 3 (strong) beams (coverage changes discussed in Section 2.1.1). Despite our use of three strong beams, there are still large regions of missing data in our monthly gridded dataset, e.g., the missing data in the Laptev/East Siberian Sea shown in Figure 7 despite the monthly CDR ice concentrations showing concentrations greater than $50 \%$ in that same region. Data drop-out is often caused by the presence of clouds and the resultant atmospheric scattering impacts on

415 ATLAS retrievals. Our interpolated/smoothed variables of freeboard, snow depth and thickness data (Figure 7i-j) do not substantially increase coverage in these regions, which was in-part by design to avoid over-extrapolation of our thickness estimates. In general, the monthly gridded data gaps are limited but should be considered when using these data to assess regional and basin-scale thickness variability.

Our following analysis of the monthly gridded ICESat-2 winter Arctic sea ice thickness data is a subset of the

420 analysis presented in an online interactive Jupyter Book: https://nicolekeeney.com/icesat2-book. The Jupyter Book consists of a series of Jupyter Notebooks that provide all code and analysis output (written in the Open-Source Python programming language) for demonstrating and sharing our thickness analysis workflow. The development of the Jupyter Book was motivated by the desire for transparency and the broader goals of facilitating more open science, but also the desire to provide a simple mechanism for interested users to explore regions and time periods not shown here. For example, the

425 Jupyter Book allows users to adapt the code interactively (either locally or using Binder) to select months and regions of interest to explore characteristics of this dataset beyond the core figures we show here. 
In Figure 8 we show the seasonal evolution of winter freeboard, snow depth/density and sea ice thickness from our IS2SITMOGR4 v2 monthly gridded dataset. The results shown in Figure 8 are again restricted to our Inner Arctic Ocean domain using the included NSIDC Arctic region mask (Figure S3) to simplify interpretation and avoid regions of higher uncertainty within the more peripheral seas of the Arctic. The data within this domain in September and October is generally lower concentration ( $40-60 \%$ on average, Figure $8 \mathrm{e}$ ), than the proceeding months ( $\sim 90 \%$ in November and near $100 \%$ in December through April), so changes in early winter are still strongly influenced by the changing coverage of sea ice as the ice pack refreezes. We thus mainly focus on analysing November to April changes, the period in which we also have full monthly data available across all three winters.

Mean monthly Inner Arctic Ocean sea ice freeboard from ATL10 show a monotonic increase from $\sim 23 \mathrm{~cm}$ in November 2018 to $39 \mathrm{~cm}$ in April 2019. Mean monthly freeboards in November 2019 are similar to 2018, but consistently lower in subsequent months (lower by $\sim 2-3 \mathrm{~cm}$ ). Mean freeboards in November 2020 are significantly lower than the previous two winters $(20 \mathrm{~cm}$ mean, so lower by $\sim 2-3 \mathrm{~cm}$ ), and are similar or lower than the 2019-2020 monthly means (lower by $\sim 1-2 \mathrm{~cm}$ ).

Mean monthly Inner Arctic Ocean snow depths from the redistributed NESOSIM v1.1 output monotonically increase from $\sim 14 \mathrm{~cm}$ in November 2018 to $\sim 25 \mathrm{~cm}$ in April 2019, increasing more rapidly between January and April than between November and January. Snow depths in the 2019-2020 winter show a similar seasonal evolution but with snow depths consistently $\sim 2 \mathrm{~cm}$ thinner than the 2018-2019 monthly means. The 2020-2021 snow depths are similar to 20192020, showing thicker snow in January 2021 compared to January 2020 but thinner snow in April 2021 than April 2020 and 2019. The mean seasonal snow density evolution is similar across the three winters, with the 2020-2021 density lower in November than the previous winters but notably higher than the previous winters between February and April.

Our mean monthly estimates of Inner Arctic Ocean sea ice thickness show an increase from $\sim 1.25 \mathrm{~m}+/-0.3 \mathrm{~m}$ in November 2018 to $2.12 \mathrm{~m}$ +/- $0.35 \mathrm{~m}$ in April 2019, with the monthly thickness increasing more rapidly between November and February than between February and April. The 2019-2020 monthly mean thickness evolution is similar to 2018-2019 winter, but with a lower April 2020 mean thickness of $2.00 \mathrm{~m}+/-0.35 \mathrm{~m}$ compared to April 2019 (2.12 m +/- $0.35 \mathrm{~m})$. The 2020-2021 mean thicknesses are significantly thinner in November through February compared to the previous two winters, $\sim 0.95 \mathrm{~m}+/-0.3 \mathrm{~m}$ in November 2020 to $2.00 \mathrm{~m}$ +/- $0.35 \mathrm{~m}$ in April 2021. Analyzing just these three winters, we observe significant differences in winter Inner Arctic Ocean thickness, with variability in the NESOSIM snow depth (and density to a lesser extent) modulating a significant component of the seasonal freeboard differences observed by ICESat-2. For example: thinner 2019-2020 snow compared to 2018-2019 mitigate the thinner freeboard and results in similar mean thickness across both winters; thinner April 2021 snow compared to 2020 and 2019 April snow mitigates the thinner freeboard and similarly results in a similar mean thickness. It is also worth noting that the fraction of multi-year ice is inversely related to the thickness rankings - i.e., the 2018-2019 winter shows the lowest mean fraction of multi-year ice in this three-year period, but also shows the highest freeboard, snow depths and thickness. Three years is not a long enough record to establish true 
https://doi.org/10.5194/tc-2022-39

Preprint. Discussion started: 16 February 2022

(c) Author(s) 2022. CC BY 4.0 License.

\section{(c) $\underset{\mathrm{BY}}{\mathrm{BV}}$}

relationships, but the results highlight the potential pitfalls of inferring thickness from ancillary quantities such as freeboard or multi-year ice fraction if one is interested in tracking interannual changes.

To assess the spatial distribution of the winter changes discussed above, Figure 9 shows maps of winter mean (November to April) freeboard, snow depth and thickness from IS2SITMOGR4 v2, while Figure 10 shows anomalies relative to the three-winter mean. The winter mean freeboard maps show positive anomalies in the 2018-2019 winter in the region directly north of Greenland and the Canadian Arctic Archipelago (CAA), the region of the Arctic where we generally expect to observe the thickest freeboard, snow depth and thickness. Some small negative freeboard anomalies are observed in the Beaufort Sea and within Bering Strait. The 2018-2019 snow depth anomalies are relatively small and regionally variable while the 2018-2019 thickness anomalies are similar to the freeboard anomalies except for the additional weak negative anomalies that extend from the Beaufort Sea across the Central Arctic and into the Barents Sea. The 2019-2020 freeboard anomalies show instead weak regionally variable anomalies, including negative anomalies along the CAA coast. The 2019-2020 snow depth anomalies show similar spatial distributions to freeboard except for the positive Laptev Sea snow depth anomalies and stronger positive central Arctic snow depth anomalies. The impact on 2019-2020 thickness is weak negative anomalies in the eastern Arctic and some strong negative anomalies along (and within) the CAA coast and weak positive anomalies in the Central Arctic. Data within the CAA should be treated with caution as the lack of leads in these narrow channels often hinder freeboard/thickness retrievals (these are not included in the mean timeseries plots shown in Figure 8 partly for this reason). The 2020-2021 freeboard anomalies show a regional distribution almost opposite to 20182019, with strong negative anomalies in the Southern Central Arctic region north of Greenland/CAA and towards the Barents Sea, with weak positive anomalies in the Beaufort, Laptev, Bering Seas and Hudson Bay. The spatial distribution in the 2020-2021 snow depth anomaly is again variable and notable for the strong negative anomalies within the Barents Sea. The strong negative Barents Sea snow depth anomalies mitigate much of the negative freeboard anomalies observed by ICESat-2, meaning the impact on the 2020-2021 thickness is strong negative anomalies throughout much of the Central Arctic region and into the Chukchi Sea. The low freeboards within the Barents Sea region and the increased potential for surface flooding in this region (Granskog et al., 2017), a process which is not currently simulated by NESOSIM, means those results should also be treated with caution (this region is mostly excluded from our Inner Arctic Ocean domain, Figure S3). Monthly maps and anomalies of all IS2SITMOGR4 v2 variables have been generated and provided in the relevant Jupyter Book page (https://nicolekeeney.com/icesat2-book/sea_ice_characteristics).

In Figure 11 we show a comparison of these three winters of Inner Arctic Ocean sea ice thickness (and associated uncertainties) with thickness estimates derived from PIOMAS. As opposed to the CryoSat-2 comparisons, we focus here on basin-scale comparisons to assess the broad level of agreement when using both datasets for assessing the winter seasonal cycle and interannual thickness variability - arguably the primary use of PIOMAS data to-date. In general, both seasonal timeseries show good agreement, however PIOMAS is generally thicker than ICESat-2, especially by the end of winter in all three years of our analysis (20 to $40 \mathrm{~cm}$ thicker). These differences are within the spread of our ICESat-2 systematic uncertainty estimates, however. Spatial difference plots are generated and provided in the Jupyter Book 
https://doi.org/10.5194/tc-2022-39

Preprint. Discussion started: 16 February 2022

(c) Author(s) 2022. CC BY 4.0 License.

\section{(c) $\underset{\mathrm{BY}}{\mathrm{BV}}$}

495 (https://nicolekeeney.com/icesat2-book/pio_vs_is2) which highlight the stronger disagreement at regional scales, e.g., PIOMAS not simulating the thicker ice north of the Greenland and CAA coasts shown in our ICESat-2 data.

\subsubsection{Key drivers of winter thickness differences}

The regional anomaly maps allude to a strong ice type dependency as some of the more significant winter anomalies are observed within the thicker/older ice of the Central Arctic. To explore this further, Figures 12 and 13 show the seasonal timeseries of IS2SITMOGR4 v2 but delineated by ice type (data still masked outside the Inner Arctic Ocean domain). Figure 12 shows the mean seasonal time series of regions identified as first-year ice (FYI) only. The differences in FYI freeboard and snow depth in November/December are small $(<1 \mathrm{~cm})$ across the three winters, with the higher 20182019 FYI freeboard and snow depth only appearing later in the season compared to the 'all ice' analysis. The resultant FYI sea ice thickness winter timeseries comparison is notable for its consistency across the three winters (interannual thickness differences $<15 \mathrm{~cm}$ across all months). Figure 13 shows the mean seasonal time series of regions identified as multiyear ice (MYI) only. The interannual MYI differences across most variables are higher than the FYI differences. The 2018 November MYI freeboards are $5 \mathrm{~cm}$ higher than the 2019 and 2020 Novembers. This difference largely persists through the winter until February onwards when the 2019-2020 freeboard increases and reduces the interannual spread, driven by the coincident strong increase in 2019-2020 snow depths. The result is MYI thickness that exhibits similar seasonal cycles across the three winters but with differences of 10 to $50 \mathrm{~cm}$ that largely persist across the three winters.

These ice type differences align with our general understanding of winter sea ice growth - thinner ice is more responsive to atmospheric forcing and can thicken rapidly due to its reduced insulation (the negative feedback of ice growth) so small differences in the thickness of thin FYI at the start of winter are not expected to be good predictors of end-of-winter thickness (Petty et al., 2018b). Conversely, MYI is significantly thicker at the start of winter, meaning thickness anomalies

515 are more likely to persist through winter as the ice is more insulated and less sensitive to atmospheric forcing. The differences in MYI thickness at the start of our three winters appears to provide a strong control on the total (combined MYI and FYI) winter thickness anomalies across all months, albeit in this limited record. Previous studies based on CryoSat-2 derived Arctic sea ice thickness estimates have highlighted the significant role of variable summer conditions in determining start of winter ice thickness anomalies and thus total winter thickness (and volume) anomalies (Tilling et al., 2015; Kwok, 2015). More specifically, a sharp increase in the start-of-winter 2013 Arctic thickness/volume was related to reductions in the duration of the summer melt season (Tilling et al., 2015) and also to dynamically driven convergence of ice within the Central Arctic (Kwok, 2015). The observed positive autumn 2013 thickness anomaly persisted through winter months, as in our 2018/2019 results. We do not seek to provide a similar level of analysis in this study as our primary goal was to highlight and describe this new thickness dataset, but the agreement with our prior physical understanding is encouraging.

To better understand some of the more regional differences, the spatial thickness maps in Figure 10 have been overlaid with winter mean ice drifts from the monthly OSI SAF global low resolution ice drift product (Lavergne et al., 2010). In general, the mean circulation across these three winters are similar - featuring anti-clockwise Beaufort Gyre 
circulations and Transpolar drifts, but with some key differences. For example, ice drifts through the southern Beaufort Sea in 2018-2019 winter were stronger than the 2019-2020 and 2020-2021 drifts, which is likely associated with the positive freeboard/snow depth/thickness anomalies observed in the Chukchi Sea and negative anomalies in the Beaufort Sea in 20182019. Disentangling cause from effect is challenging as ice drift is strongly influenced by the sea ice conditions (Petty et al., 2016), however the strong association between drift patterns and thickness anomalies is again encouraging. Stronger ice drift anomalies are apparent when assessing monthly (not seasonal) differences, which can be explored more in the relevant Jupyter Book page (https://nicolekeeney.com/icesat2-book/sea_ice_characteristics).

Finally, to briefly explore any possible winter atmospheric drivers of these differences, Figure 14 shows an analysis of ERA5 near-surface $(2 \mathrm{~m}$ ) air temperatures and downwelling longwave radiation over our Inner Arctic Ocean domain. The 2018-2019 winter shows lower temperatures and downward longwave flux at the start of winter (November through January) compared to 2019-2020 and 2020-2021, but higher temperatures and downward longwave flux in the middle-end of winter (February and March) compared to the following winters. April temperatures and downward longwave are similar in 201820919 to 2019-2020. The near-surface atmospheric conditions are strongly coupled to variability in the sea ice state so, as in the ice drift analysis, it is challenging to differentiation cause from effect. Nevertheless, it appears that the near-surface atmospheric conditions during the start-middle of each winter are strongly coupled with the interannual ice conditions, promoting persistence of the interannual start-of-winter thickness anomalies (especially for the thicker MYI). The atmospheric analysis can be viewed and explored more in the relevant Jupyter Book page (https://nicolekeeney.com/icesat2book/atmospheric_variables).

\section{Summary}

In this study we provided an impact assessment of upgrades to the input data used to produce ICESat-2-derived winter Arctic sea ice thickness estimates shown in Petty et al., (2020), and an extended analysis of the upgraded monthly gridded winter Arctic thickness dataset across the three winters profiled since the launch of ICESat-2 in September 2018.

Input data upgrades include the ICESat-2 ATL10 freeboards (Release 002 to 005, rel002 to rel005) and NASA Eulerian Snow On Sea Ice Model (NESOSIM, version 1.0 to version 1.1) snow loading. A key change in ATL10 data was the removal of misclassified leads from the determination of sea surface and thus freeboard in rel003. This was thought to be the primary cause of the increase in freeboard observed in January 2019 and April 2019 in rel003 data compared to rel002, together with the more significant primary mode of lower freeboards in November 2018 rel003 data. The rel003-derived monthly gridded winter Arctic ice thickness data show improved comparisons with thickness estimates produced from ESA's CryoSat-2 using the same input assumptions across all 2018-2019 winter months (lower mean biases and standard deviations, higher correlations) compared to rel002-derived estimates. Later releases of ATL10 (rel004 and rel005) involved only minor changes to the freeboard algorithms and thus exhibit less significant changes in the observed freeboard distributions. The different releases also show slight differences in ATL10 data coverage, due primarily to the changes 
associated with dark lead usage, but also the inclusion/filtering of satellite calibration scan data. Our updated (version 2) monthly gridded winter Arctic sea ice thickness dataset now utilizes all three strong beams and includes new interpolated/smoothed data variables to mitigate these coverage issues.

Our upgraded version of NESOSIM (version 1.1) presented in this study includes a new wind-driven atmosphere snow loss term, CloudSat-scaled ERA5 snowfall forcing (Cabaj et al., 2020) and some more minor bug fixes. NESOSIM v1.1 was also re-calibrated (heuristically) using spring Arctic snow depth estimates obtained by NASA's Operation IceBridge airborne mission (a gridded consensus product derived in this study). NESOSIM v1.1 generally shows similar snow depths to NESOSIM v1.0, resulting in a less significant impact on Arctic winter sea ice thickness compared to the rel002 to rel003 freeboard changes. A new NESOSIM v1.1 climatology (from 2010-2020 daily means) was introduced towards the production of a more near-real time thickness retrievals from the forthcoming Quick Look ATL10 freeboard dataset.

Finally, we presented estimates of winter Arctic sea ice thickness from this updated monthly gridded winter Arctic sea ice thickness dataset (IS2SITMOGR4 v2) over the past three winter seasons of data collection (November 2018 - April 2021, September 2019 - April 2020 and September 2020 - April 2021). Our results showed clear differences in mean winter Arctic sea ice thickness within our Inner Arctic Ocean domain across the three winters profiled, due primarily to differences in the multiyear ice thickness across the three winters (multiyear ice thinning of 10 to $50 \mathrm{~cm}$ each year across the three winters analysed). Interannual changes in snow depth provide significant regional/monthly impacts on our thickness results mitigating some (or in some cases all) of the impact from interannual differences in Arctic winter freeboards observed by ICESat-2. Our results provide further evidence of the importance of accurate snow representation when assessing interannual variability in winter Arctic sea ice thickness from satellite altimetry (Bunzel et al., 2018; Mallett et al., 2021). Specific regional thickness anomalies, e.g. in the Southern Beaufort and Chukchi seas, were associated with interannual ice drift anomalies. Our mean Inner Arctic Ocean thickness estimates showed good agreement with those generated from the PIOMAS v2.1 reanalysis in terms of the seasonal cycle and interannual differences, although more significant differences were noted at regional scales.

\subsection{Future work}

ICESat-2/ATL10: Work is still on-going to re-introduce dark leads to the sea surface and freeboard algorithm in ATL10, which requires a new filter to skilfully discriminate dark lead segments (low photon rate) from segments with photon attenuation driven by the presence of clouds. The variable properties of clouds and their impact on photon attenuation, together with the limited availability of coincident imagery for validation (as used in Petty et al., 2021) makes this development challenging. An additional near-term goal related to ATL10 is the plan to utilize all six beams (or at least

590 the three strong beams) concurrently to produce two-dimensional interpolated fields of sea surface height, as opposed to the independent beam processing currently utilized. However, residual height biases of several centimetres are still observed between the beams as of Release 005 (updated from the analysis shown in Bagnardi et al., 2021, not shown), hindering this 
development. More sophisticated sea surface interpolation methods should also be explored (Landy et al., 2021). Additional algorithm development efforts are on-going towards the next data release (Release 006), expected sometime later in 2022.

NESOSIM: Work is on-going to utilize a Markov Chain Monte Carlo to further calibrate NESOSIM v1.1 providing better constraints on the free parameters and also more robust uncertainty estimates of snow depth and density from this model framework (Cabaj et al., 2021). This approach benefits from the low computational cost of NESOSIM, allowing thousands of model simulations to be generated across plausible model parameter space. Additional physical upgrades are still desired, e.g., the introduction of a snow melt parameterization to extend NESOSIM through summer. However, additional reliable ground-truth data at regional/basin-scales are needed to calibrate and validate such development activities.

ICESat-2-derived sea ice thickness: Our primary focus of the three-winter thickness assessment was the monthly gridded winter Arctic thickness dataset (IS2SITMOGR4). However, raw (and $10 \mathrm{~km}$ smoothed) along-track data at the segment resolution of ATL10 ( $20 \mathrm{~m})$ are also available (IS2SITDAT4, data shown in Figure 5), which provide higher fidelity information regarding the sea ice state than the monthly gridded estimates. Work is currently on-going to assess the winter Arctic sea ice thickness distribution from these data including comparisons with model-based estimates. Continued refinement and/or redevelopment of the snow redistribution scheme is expected. We also hope to combine these data with new ICESat-2-derived floe size estimates (Petty et al., 2021) towards a joint floe size-thickness distribution. This dataset is more computationally demanding but increasing access to high performance computing environments (e.g., cloud compute platforms) should help increase its usability. The extension of NESOSIM through summer months will help enable summer preliminary production of summer Arctic thickness estimates.

Sea ice thickness reconciliation: The improved correspondence between our ICESat-2 derived estimates of winter Arctic sea ice thickness and those generated from ESA's CryoSat-2 are encouraging. There are clear advantages (and disadvantages) from estimating sea ice thickness from either radar or laser altimetry, which need to be better considered and utilized for constraining total Arctic (and eventually Antarctic) sea ice volume. Radar altimeters, e.g., CryoSat-2, are highly sensitive to leads and are unaffected by clouds, providing benefits to both the quality and coverage of data collected. In contrast, laser altimeters (e.g., ICESat/ICESat-2) generally provide higher resolution data and obtain more precise estimates of the snow-covered ice surface height (and thus total freeboard) compared to the arguably less distinct/certain ice-snow interface height (and thus ice freeboard) obtained by typical radar altimeters. The effective radar penetration depth at $\mathrm{Ku} / \mathrm{Ka}$ band is generally considered to come from the ice-snow interface although recent studies continue to challenge this (Nandan et al., 2017, King et al., 2018). In both cases, uncertainties in the derived freeboard estimates are combined with uncertainties in the various input assumptions (snow loading, sea ice density) to provide total thickness uncertainty estimates. Constraining the various input uncertainties and residual biases remains challenging, which points to the need for improved exploitation of existing ground-truth data and further field and airborne campaigns considering the fast-changing Arctic. Regardless, improvements to the underlying freeboard algorithms and input assumptions are urgently needed as we seek to reconcile these datasets and hopefully move towards multi-sensor thickness assessments (increasing coverage and data 
https://doi.org/10.5194/tc-2022-39

Preprint. Discussion started: 16 February 2022

(c) Author(s) 2022. CC BY 4.0 License.

(c) (i)

quality). Planning is underway for a coordinated intercomparison exercise around new semi-synchronous along-track measurements available since the CRYO2ICE orbit alignment (https://earth.esa.int/eogateway/missions/cryosat/cryo2ice).

\section{Code availability}

630 Our analysis of the monthly gridded winter Arctic thickness data described above (Figures 8-14) have been summarized and made available through an online Jupyter Book (https://nicolekeeney.com/icesat2-book/home.html). Interested users are able to view the various figures (and additional plots not shown here), view the code used to generate them, and also interactively run the analysis locally or online (using the associated Binder links, https://mybinder.org), e.g., changing the domain and/or months of interest. It is our expectation that this Jupyter Book will be updated as new IS2SITMOGR4 data are created and made public to enable continued assessments of winter Arctic thickness change. A version tagged version of this Jupyter Book will be obtained and archived on Zenodo on completion of peer review.

NESOSIM is available on GitHub (https://github.com/akpetty/NESOSIM/) and the version 1.1 release used in this study has been tagged as a specific release on GitHub and archived on Zenodo (https://doi.org/10.5281/zenodo.4448356).

The original sea ice thickness processing code presented in Petty et al., (2020) is available on GitHub (https://github.com/akpetty/ICESat-2-sea-ice-thickness, all in the open-source language Python). We plan to update this using the small upgrades made to our processing chain on completion of this peer-review.

\section{Data availability}

The monthly gridded winter Arctic sea ice thickness data derived in this study (IS2SITMOGR4, version 2) is being made available through the National Snow and Ice Data Center (NSIDC) (https://nsidc.org/data/IS2SITMOGR4, currently

645 showing version 1 from Petty et al., 2020). The along-track (raw and $10 \mathrm{~km}$ mean) Arctic sea ice thickness estimates are also in the process of being ingested and made publicly available through the NSIDC (IS2SITDAT4, we expect the data portal will be made available during peer review).

The ICESat-2 ATL10 sea ice freeboard data (currently Release 005) can be obtained from the NSIDC (https://nsidc.org/data/atl10). NSIDC generally maintains an archive of ICESat-2 data from the current and previous release, so currently Release 004 can be obtained from the NSIDC also (https://nsidc.org/data/at110/versions/4).

The output from our NESOSIM v1.1 model framework from 1980-2021 and the NESOSIM v1.1 climatology presented here has been archived on Zenodo (https://doi.org/10.5281/zenodo.5164314).

Daily and monthly NASA Climate Data Record (CDR) version 4 ice concentration data were obtained from the NSIDC (https://nsidc.org/data/G02202). ERA5 estimates of daily snowfall, winds and near surface temperature and 655 downwelling longwave radiation were obtained from the European Centre for Medium-Range Weather Forecasts (ECMWF) Copernicus Climate Change Service Climate Data Store (https://cds.climate.copernicus.eu).EUMETSAT OSI SAF ice 
https://doi.org/10.5194/tc-2022-39

Preprint. Discussion started: 16 February 2022

(c) Author(s) 2022. CC BY 4.0 License.

(c) (i)

motion data were obtained through their web portal (http://osisaf.met.no/p/ice/, last access: 1 May 2021). OSI SAF ice type data were obtained from their ftp repository (ftp://osisaf.met.no/prod/ice/type/, last access 1 May 2021). Polar Pathfinder version 4 ice drifts were obtained from the NSIDC (https://nsidc.org/data/nsidc-0116/versions/4).

The NASA GSFC CryoSat-2 (CS-2) Arctic sea ice thickness data were obtained from the NSIDC (https://nsidc. org/data/RDEFT4, last access: 1 May 2019). The CPOM CS-2 thickness data were obtained from their web portal (http://www. cpom.ucl.ac.uk/csopr/seaice.html, last access: 1 May 2019). The AWI CS-2 thickness data were obtained from their web portal (http://data.seaiceportal.de/data/cryosat2/version2.1/13c_grid, last access: 1 May 2019). The NASA JPL CS2 thickness data were obtained directly from Dr. Ron Kwok.

\section{Author contributions}

AP led the study, produced the updated NESOSIM v1.1 framework/output and ICESat-2 thickness estimates (along-track and gridded). NK produced the Jupyter Book with assistance from AP and helped produce the new interpolated thickness variables. AC and PK helped AP produce the updated NESOSIM framework and output. MB generated the release and beam coverage assessments and provided key input on ATL10 upgrades. AP wrote the manuscript with input/edits provided from all authors.

\section{Competing interests}

The authors declare that they have no conflict of interest.

\section{Acknowledgements}

We would like to thank the ICESat-2 scientists and engineers for their continued efforts in enabling the production of the high-quality freeboard data analysed in this study. Thanks also to the NSIDC team for their continued support in documenting and hosting our derived winter Arctic sea ice thickness data.

\section{References}

Bagnardi, M., Kurtz, N. T., Petty, A. A., and Kwok, R.: Sea Surface Height Anomalies of the Arctic Ocean From ICESat-2: A First Examination and Comparisons With CryoSat-2, 48, e2021GL093155, https://doi.org/10.1029/2021GL093155, 2021.

680 Barrett, A. P., Stroeve, J. C., and Serreze, M. C.: Arctic Ocean Precipitation From Atmospheric Reanalyses and Comparisons With North Pole Drifting Station Records, 125, e2019JC015415, https://doi.org/10.1029/2019JC015415, 2020.

Breivik, L. A., Eastwood, S., and Lavergne, T.: Use of C-Band Scatterometer for Sea Ice Edge Identification, 50, 26692677, https://doi.org/10.1109/TGRS.2012.2188898, 2012. 
https://doi.org/10.5194/tc-2022-39

Preprint. Discussion started: 16 February 2022

(c) Author(s) 2022. CC BY 4.0 License.

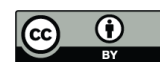

Bunzel, F., Notz, D., and Pedersen, L. T.: Retrievals of Arctic Sea-Ice Volume and Its Trend Significantly Affected by Interannual Snow Variability, 45, 11,751-11,759, https://doi.org/10.1029/2018GL078867, 2018.

Cabaj, A., Kushner, P. J., Fletcher, C. G., Howell, S., and Petty, A. A.: Constraining Reanalysis Snowfall Over the Arctic Ocean Using CloudSat Observations, 47, e2019GL086426, https://doi.org/10.1029/2019GL086426, 2020.

Community, S.: Arctic Sea Ice in CMIP6, 47, e2019GL086749, https://doi.org/10.1029/2019GL086749, 2020.

Dee, D. P., Uppala, S. M., Simmons, A. J., Berrisford, P., Poli, P., Kobayashi, S., Andrae, U., Balmaseda, M. A., Balsamo, G., Bauer, P., Bechtold, P., Beljaars, A. C. M., van de Berg, L., Bidlot, J., Bormann, N., Delsol, C., Dragani, R., Fuentes, M., Geer, A. J., Haimberger, L., Healy, S. B., Hersbach, H., Holm, E. V., Isaksen, L., Kallberg, P., Kahler, M., Matricardi, M., McNally, A. P., Monge-Sanz, B. M., Morcrette, J.-J., Park, B.-K., Peubey, C., de Rosnay, P., Tavolato, C., Thepaut, J.-N., and Vitart, F.: The ERA-Interim reanalysis: configuration and performance of the data assimilation system, 137, 553-597, https://doi.org/10.1002/qj.828, 2011.

695 Giles, K. A., Laxon, S. W., Wingham, D. J., Wallis, D. W., Krabill, W. B., Leuschen, C. J., McAdoo, D., Manizade, S. S., and Raney, R. K.: Combined airborne laser and radar altimeter measurements over the Fram Strait in May 2002, Remote Sensing of Environment, 111, 182-194, https://doi.org/10.1016/j.rse.2007.02.037, 2007.

Granskog, M. A., Rösel, A., Dodd, P. A., Divine, D., Gerland, S., Martma, T., and Leng, M. J.: Snow contribution to firstyear and second-year Arctic sea ice mass balance north of Svalbard, 122, 2539-2549, https://doi.org/10.1002/2016JC012398, 2017.

Hendricks, S. and Ricker, R.: User guide-AWI CryoSat-2 sea ice thickness data product (v1.2). Retrieve from http://epic.awi.de/ 41242/, 2016.

Hersbach, H., Bell, B., Berrisford, P., Hirahara, S., Horányi, A., Muñoz-Sabater, J., Nicolas, J., Peubey, C., Radu, R., Schepers, D., Simmons, A., Soci, C., Abdalla, S., Abellan, X., Balsamo, G., Bechtold, P., Biavati, G., Bidlot, J., Bonavita,

705 M., De Chiara, G., Dahlgren, P., Dee, D., Diamantakis, M., Dragani, R., Flemming, J., Forbes, R., Fuentes, M., Geer, A., Haimberger, L., Healy, S., Hogan, R. J., Hólm, E., Janisková, M., Keeley, S., Laloyaux, P., Lopez, P., Lupu, C., Radnoti, G., de Rosnay, P., Rozum, I., Vamborg, F., Villaume, S., and Thépaut, J.-N.: The ERA5 global reanalysis, 146, 1999-2049, https://doi.org/10.1002/qj.3803, 2020.

King, J., Howell, S., Derksen, C., Rutter, N., Toose, P., Beckers, J. F., Haas, C., Kurtz, N., and Richter-Menge, J.: 710 Evaluation of Operation IceBridge quick-look snow depth estimates on sea ice, Geophys. Res. Lett., 42, 2015GL066389, https://doi.org/10.1002/2015GL066389, 2015.

King, J., Skourup, H., Hvidegaard, S. M., Rösel, A., Gerland, S., Spreen, G., Polashenski, C., Helm, V., and Liston, G. E.: Comparison of Freeboard Retrieval and Ice Thickness Calculation From ALS, ASIRAS, and CryoSat-2 in the Norwegian Arctic, to Field Measurements Made During the N-ICE2015 Expedition, J. Geophys. Res. Oceans, n/a-n/a, 715 https://doi.org/10.1002/2017JC013233, n.d.

Koenig, L. S., Ivanoff, A., Alexander, P. M., MacGregor, J. A., Fettweis, X., Panzer, B., Paden, J. D., Forster, R. R., Das, I., McConnell, J. R., Tedesco, M., Leuschen, C., and Gogineni, P.: Annual Greenland accumulation rates (2009-2012) from airborne snow radar, The Cryosphere, 10, 1739-1752, https://doi.org/10.5194/tc-10-1739-2016, 2016.

Kurtz, J. C. and Harbeck, J.: CryoSat-2 Level 4 Sea Ice Elevation, Freeboard, and Thickness, Version 1. Boulder, Colorado

USA: NASA DAAC at the National Snow and Ice Data Center, https://doi.org/0.5067/96JO0KIFDAS8, 2017. 
https://doi.org/10.5194/tc-2022-39

Preprint. Discussion started: 16 February 2022

(c) Author(s) 2022. CC BY 4.0 License.

\section{(c) (i)}

Kurtz, N. T., Farrell, S. L., Studinger, M., Galin, N., Harbeck, J. P., Lindsay, R., Onana, V. D., Panzer, B., and Sonntag, J. G.: Sea ice thickness, freeboard, and snow depth products from Operation IceBridge airborne data, 7, 1035-1056, https://doi.org/10.5194/tc-7-1035-2013, 2013.

Kurtz, N. T., Galin, N., and Studinger, M.: An improved CryoSat-2 sea ice freeboard retrieval algorithm through the use of waveform fitting, 8, 1217-1237, https://doi.org/10.5194/tc-8-1217-2014, 2014.

Kwok, R.: Sea ice convergence along the Arctic coasts of Greenland and the Canadian Arctic Archipelago: Variability and extremes (1992-2014), 42, 7598-7605, https://doi.org/10.1002/2015GL065462, 2015.

Kwok, R.: Arctic sea ice thickness, volume, and multiyear ice coverage: losses and coupled variability (1958-2018), Environ. Res. Lett., 13, 105005, https://doi.org/10.1088/1748-9326/aae3ec, 2018.

730 Kwok, R. and Cunningham, G. F.: ICESat over Arctic sea ice: Estimation of snow depth and ice thickness, J. Geophys. Res., 113, C08010, https://doi.org/10.1029/2008JC004753, 2008.

Kwok, R. and Cunningham, G. F.: Variability of Arctic sea ice thickness and volume from CryoSat-2, 373, https://doi.org/10.1098/rsta.2014.0157, 2015.

Kwok, R., Cunningham, G. F., Hoffmann, J., and Markus, T.: Testing the ice-water discrimination and freeboard retrieval

735 algorithms for the ICESat-2 mission, Remote Sensing of Environment, 183, 13-25, https://doi.org/10.1016/j.rse.2016.05.011, 2016.

Kwok, R., Kurtz, N. T., Brucker, L., Ivanoff, A., Newman, T., Farrell, S. L., King, J., Howell, S., Webster, M. A., Paden, J., Leuschen, C., MacGregor, J. A., Richter-Menge, J., Harbeck, J., and Tschudi, M.: Intercomparison of snow depth retrievals over Arctic sea ice from radar data acquired by Operation IceBridge, 11, 2571-2593, https://doi.org/10.5194/tc-11-2571-

$740 \quad 2017,2017$.

Kwok, R., Kacimi, S., Markus, T., Kurtz, N. T., Studinger, M., Sonntag, J. G., Manizade, S. S., Boisvert, L. N., and Harbeck, J. P.: ICESat-2 surface height and sea-ice freeboard assessed with ATM lidar acquisitions from Operation IceBridge, 44, 11228-11236, https://doi.org/10.1029/2019GL084976, 2019a.

Kwok, R., Markus, T., Kurtz, N. T., Petty, A. A., Neumann, T. A., Farrell, S. L., Cunningham, G. F., Hancock, D. W., 745 Ivanoff, A., and Wimert, J. T.: Surface Height and Sea Ice Freeboard of the Arctic Ocean From ICESat-2: Characteristics and Early Results, 124, 6942-6959, https://doi.org/10.1029/2019JC015486, $2019 \mathrm{~b}$.

Kwok, R., Petty, A., Cunningham, G., Markus, T., Hancock, D., Ivanoff, A., Wimert, J., Bagnardi, M., and Kurtz, N.: ATLAS/ICESat-2 L3A Sea Ice Heights, Version 5, https://doi.org/10.5067/ATLAS/ATL07.005, 2021 a.

Kwok, R., Petty, A., Cunningham, G., Markus, T., Hancock, D., Ivanoff, A., Wimert, J., Bagnardi, M., and Kurtz, N.: ATLAS/ICESat-2 L3A Sea Ice Freeboards, Version 5, https://doi.org/10.5067/ATLAS/ATL10.005, 2021b.

Kwok, R., Petty, A., Wimert, J., Bagnardi, M., Cuningham, G., Hancock, D., Ivanoff, A., and Kurtz, N.: Ice, Cloud, and Land Elevation Satellite-2 Project: Algorithm Theoretical Basis Document (ATBD) for Sea Ice Products, Release 005, https://icesat-2.gsfc.nasa.gov/science/data-products, 2021c.

Kwok, R., Petty, A. A., Bagnardi, M., Kurtz, N. T., Cunningham, G. F., Ivanoff, A., and Kacimi, S.: Refining the sea surface 755 identification approach for determining freeboards in the ICESat-2 sea ice products, 15, 821-833, https://doi.org/10.5194/tc15-821-2021, 2021d. 
https://doi.org/10.5194/tc-2022-39

Preprint. Discussion started: 16 February 2022

(c) Author(s) 2022. CC BY 4.0 License.

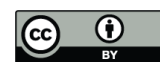

Landy, J. C., Bouffard, J., Wilson, C., Rynders, S., Aksenov, Y., and Tsamados, M.: Improved Arctic Sea Ice Freeboard Retrieval From Satellite Altimetry Using Optimized Sea Surface Decorrelation Scales, 126, e2021JC017466, https://doi.org/10.1029/2021JC017466, 2021.

760 Lavergne, T., Eastwood, S., Teffah, Z., Schyberg, H., and Breivik, L.-A.: Sea ice motion from low-resolution satellite sensors: An alternative method and its validation in the Arctic, J. Geophys. Res., 115, C10032, https://doi.org/10.1029/2009JC005958, 2010.

Laxon, S. W., Giles, K. A., Ridout, A. L., Wingham, D. J., Willatt, R., Cullen, R., Kwok, R., Schweiger, A., Zhang, J., Haas, C., Hendricks, S., Krishfield, R., Kurtz, N., Farrell, S., and Davidson, M.: CryoSat-2 estimates of Arctic sea ice thickness and volume, 40, 732-737, https://doi.org/10.1002/grl.50193, 2013.

Liston, G. E., Itkin, P., Stroeve, J., Tschudi, M., Stewart, J. S., Pedersen, S. H., Reinking, A. K., and Elder, K.: A Lagrangian Snow-Evolution System for Sea-Ice Applications (SnowModel-LG): Part I-Model Description, 125, e2019JC015913, https://doi.org/10.1029/2019JC015913, 2020.

Magruder, L. A., Brunt, K. M., and Alonzo, M.: Early ICESat-2 on-orbit Geolocation Validation Using Ground-Based Corner Cube Retro-Reflectors, 12, 3653, https://doi.org/10.3390/rs12213653, 2020.

Mallett, R. D. C., Stroeve, J. C., Tsamados, M., Landy, J. C., Willatt, R., Nandan, V., and Liston, G. E.: Faster decline and higher variability in the sea ice thickness of the marginal Arctic seas when accounting for dynamic snow cover, 15, 24292450, https://doi.org/10.5194/tc-15-2429-2021, 2021.

Markus, T., Neumann, T., Martino, A., Abdalati, W., Brunt, K., Csatho, B., Farrell, S., Fricker, H., Gardner, A., Harding, D., 775 Jasinski, M., Kwok, R., Magruder, L., Lubin, D., Luthcke, S., Morison, J., Nelson, R., Neuenschwander, A., Palm, S., Popescu, S., Shum, C., Schutz, B. E., Smith, B., Yang, Y., and Zwally, J.: The Ice, Cloud, and land Elevation Satellite-2 (ICESat-2): Science requirements, concept, and implementation, Remote Sensing of Environment, 190, 260-273, https://doi.org/10.1016/j.rse.2016.12.029, 2017.

Meier, W. N., Fetterer, F., Savoie, M., Mallory, S., Duerr, R., and Stroeve, J.: NOAA/NSIDC Climate Data Record of

Passive Microwave Sea Ice Concentration, Version 3, https://doi.org/10.7265/N59P2ZTG, 2017.

Meier, W. N., Fetterer, F., Windnagel, A. K., and Stewart, J. S.: NOAA/NSIDC Climate Data Record of Passive Microwave Sea Ice Concentration, Version 4 [September 2018 to April 2021], https://doi.org/10.7265/efmz-2t65, 2021.

Nandan, V., Geldsetzer, T., Yackel, J., Mahmud, M., Scharien, R., Howell, S., King, J., Ricker, R., and Else, B.: Effect of Snow Salinity on CryoSat-2 Arctic First-Year Sea Ice Freeboard Measurements, 44, 10,419-10,426, 785 https://doi.org/10.1002/2017GL074506, 2017.

Neumann, T. A., Martino, A. J., Markus, T., Bae, S., Bock, M. R., Brenner, A. C., Brunt, K. M., Cavanaugh, J., Fernandes, S. T., Hancock, D. W., Harbeck, K., Lee, J., Kurtz, N. T., Luers, P. J., Luthcke, S. B., Magruder, L., Pennington, T. A., Ramos-Izquierdo, L., Rebold, T., Skoog, J., and Thomas, T. C.: The Ice, Cloud, and Land Elevation Satellite -2 mission: A global geolocated photon product derived from the Advanced Topographic Laser Altimeter System, Remote Sensing of Environment, 233, 111325, https://doi.org/10.1016/j.rse.2019.111325, 2019.

Petty, A. A., Hutchings, J. K., Richter-Menge, J. A., and Tschudi, M. A.: Sea ice circulation around the Beaufort Gyre: The changing role of wind forcing and the sea ice state, J. Geophys. Res. Oceans, 121, 3278-3296, https://doi.org/10.1002/2015JC010903, 2016. 
https://doi.org/10.5194/tc-2022-39

Preprint. Discussion started: 16 February 2022

(c) Author(s) 2022. CC BY 4.0 License.

(c) (i)

Petty, A. A., Webster, M., Boisvert, L., and Markus, T.: The NASA Eulerian Snow on Sea Ice Model (NESOSIM) v1.0: initial model development and analysis, 11, 4577-4602, https://doi.org/10.5194/gmd-11-4577-2018, 2018a.

Petty, A. A., Holland, M. M., Bailey, D. A., and Kurtz, N. T.: Warm Arctic, Increased Winter Sea Ice Growth?, 45, 12,92212,930, https://doi.org/10.1029/2018GL079223, 2018 b.

Petty, A. A., Kurtz, N. T., Kwok, R., Markus, T., and Neumann, T. A.: Winter Arctic Sea Ice Thickness From ICESat-2 Freeboards, 125, e2019JC015764, https://doi.org/10.1029/2019JC015764, 2020.

800 Petty, A. A., Bagnardi, M., Kurtz, N. T., Tilling, R., Fons, S., Armitage, T., Horvat, C., and Kwok, R.: Assessment of ICESat-2 Sea Ice Surface Classification with Sentinel-2 Imagery: Implications for Freeboard and New Estimates of Lead and Floe Geometry, 8, e2020EA001491, https://doi.org/10.1029/2020EA001491, 2021.

Sallila, H., Farrell, S. L., McCurry, J., and Rinne, E.: Assessment of contemporary satellite sea ice thickness products for Arctic sea ice, 13, 1187-1213, https://doi.org/10.5194/tc-13-1187-2019, 2019.

805 Schweiger, A., Lindsay, R., Zhang, J., Steele, M., Stern, H., and Kwok, R.: Uncertainty in modeled Arctic sea ice volume, 116, https://doi.org/10.1029/2011JC007084, 2011.

Tilling, R. L., Ridout, A., Shepherd, A., and Wingham, D. J.: Increased Arctic sea ice volume after anomalously low melting in 2013, 8, 643-646, https://doi.org/10.1038/ngeo2489, 2015.

Tilling, R. L., Ridout, A., and Shepherd, A.: Estimating Arctic sea ice thickness and volume using CryoSat-2 radar altimeter data, Advances in Space Research, 62, 1203-1225, https://doi.org/10.1016/j.asr.2017.10.051, 2018.

Tschudi, M., Meier, W., Stewart, J. S., Fowler, C., and Maslanik, J.: Polar Pathfinder Daily 25 km EASE-Grid Sea Ice Motion Vectors, Version 4. Boulder, Colorado USA. NASA National Snow and Ice Data Center Distributed Active Archive Center., https://doi.org/10.5067/INAWUWO7QH7B, 2019.

Wang, C., Graham, R. M., Wang, K., Gerland, S., and Granskog, M. A.: Comparison of ERA5 and ERA-Interim near815 surface air temperature, snowfall and precipitation over Arctic sea ice: effects on sea ice thermodynamics and evolution, 13, 1661-1679, https://doi.org/10.5194/tc-13-1661-2019, 2019.

Warren, S. G., Rigor, I. G., Untersteiner, N., Radionov, V. F., Bryazgin, N. N., Aleksandrov, Y. I., and Colony, R.: Snow Depth on Arctic Sea Ice, J. Climate, 12, 1814-1829, https://doi.org/10.1175/1520-0442(1999)012<1814:SDOASI $>2.0 . C O ; 2$, 1999.

820 Zygmuntowska, M., Rampal, P., Ivanova, N., and Smedsrud, L. H.: Uncertainties in Arctic sea ice thickness and volume: new estimates and implications for trends, The Cryosphere, 8, 705-720, https://doi.org/10.5194/tc-8-705-2014, 2014. 
https://doi.org/10.5194/tc-2022-39

Preprint. Discussion started: 16 February 2022

(c) Author(s) 2022. CC BY 4.0 License.

(c) (i)

\begin{tabular}{lll}
\hline Model parameter & NESOSIM v1.0 & NESOSIM v1.1 \\
\hline New snow density, top layer $\left(\mathrm{kg} \mathrm{m}^{-3}\right)$ & 200 & 200 \\
Old snow density, bottom layer $\left(\mathrm{kg} \mathrm{m}^{-3}\right)$ & 350 & 350 \\
Wind action threshold $\left(\mathrm{m} \mathrm{s}^{-1}\right), \omega$ & 5 & 5 \\
Blowing snow coefficient $\left(\mathrm{s}^{-1}\right), \boldsymbol{\beta}$ & $2.9 \times 10^{-7}$ & $1.45 \times 10^{-7}$ \\
Atmosphere loss coefficient, $\boldsymbol{\gamma}$ & N/A & 0.15 \\
Wind packing coefficient, $\omega\left(\mathrm{s}^{-1}\right)$ & $5.8 \times 10^{-7}$ & $5.8 \times 10^{-7}$ \\
\hline Forcing data & & \\
\hline & MEDIAN-SF (Sep 2000 to Apr 2015) & \\
Snowfall & ERA-I (Sep 2018 to Apr 2019) & ERA5 (+ CloudSat scaling) \\
Near-surface winds & ERA-I & ERA5 \\
Near-surface air temperature & ERA-I & ERA5 \\
& Bootstrap (Sep 2000 to Apr 2015) & \\
Sea ice concentration & NSIDC CDRv3 (Sep 2018-Apr 2019) & NSIDC CDR v3 \\
& NSIDC v3 (Sep 2000-Apr 2015) & NSIDC v4 (Sep 1980 to April 2019) \\
Sea ice drift & OSI SAF (Sep 2018-Apr 2019) & OSI SAF (Sep 2019 to Apr 2021) \\
\hline Initial conditions & August 15th & September 1st \\
\hline Start date & &
\end{tabular}

Table 1: Model configurations for NESOSIM v1.0 and v1.1. 
https://doi.org/10.5194/tc-2022-39

Preprint. Discussion started: 16 February 2022

(C) Author(s) 2022. CC BY 4.0 License.

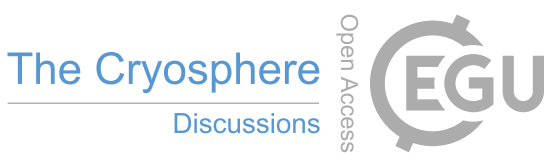

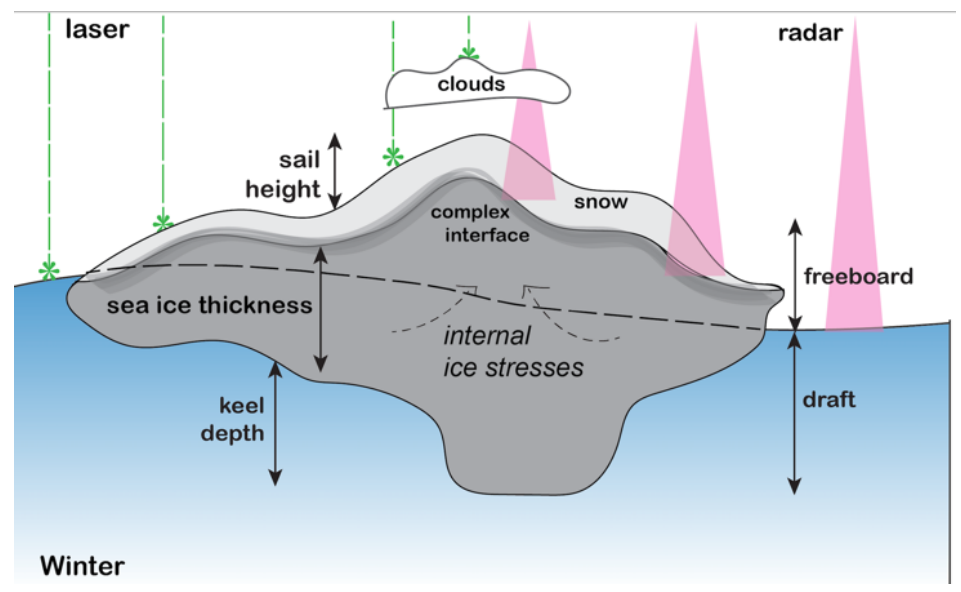

830 Figure 1: Schematic showing the typical approach and key challenges in active sea ice altimetry (laser, e.g., ICESat-2, radar, e.g., CryoSat-2) over sea ice. 
https://doi.org/10.5194/tc-2022-39

Preprint. Discussion started: 16 February 2022

(c) Author(s) 2022. CC BY 4.0 License.

\section{(c) (1)}

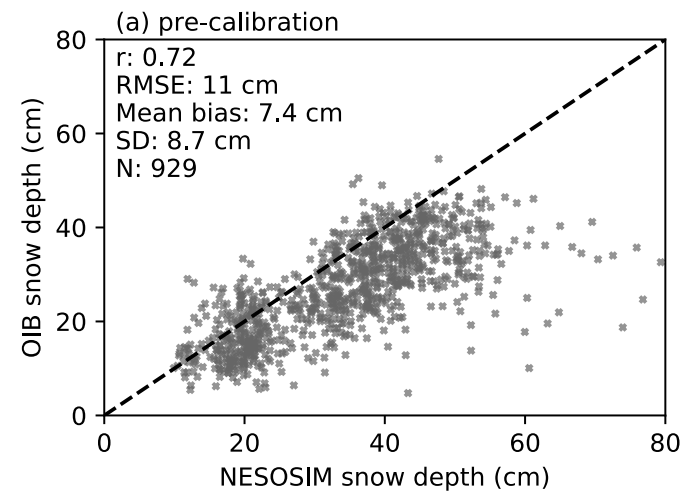

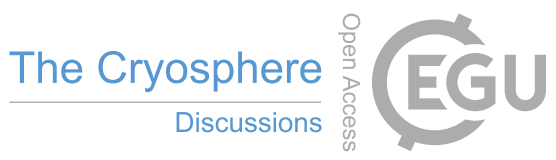

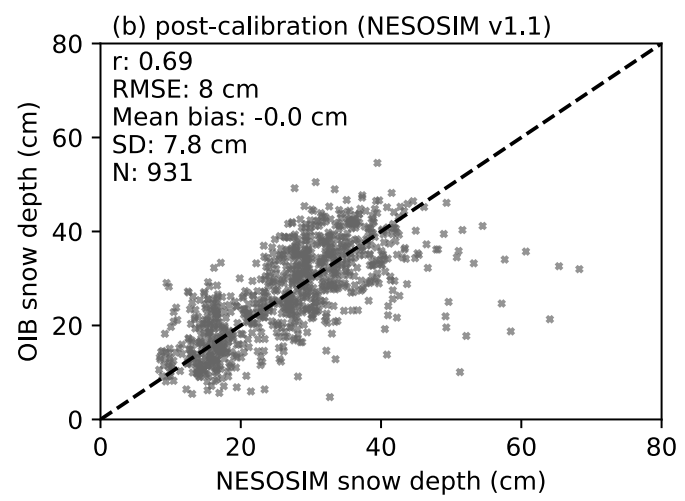

835 Figure 2: Comparison of (a) pre-calibration NESOSIM v1.1 and (b) post-calibration, NESOSIM v1.1 snow depths against spring (20102015) Arctic snow depths from gridded daily spring 2010 to 2015 median Operation IceBridge (OIB) snow depth estimates. 
https://doi.org/10.5194/tc-2022-39

Preprint. Discussion started: 16 February 2022

(c) Author(s) 2022. CC BY 4.0 License.

(c) (i)

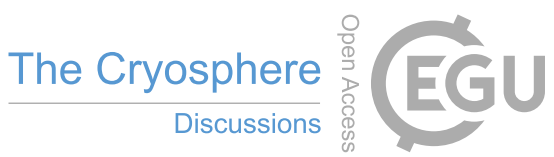
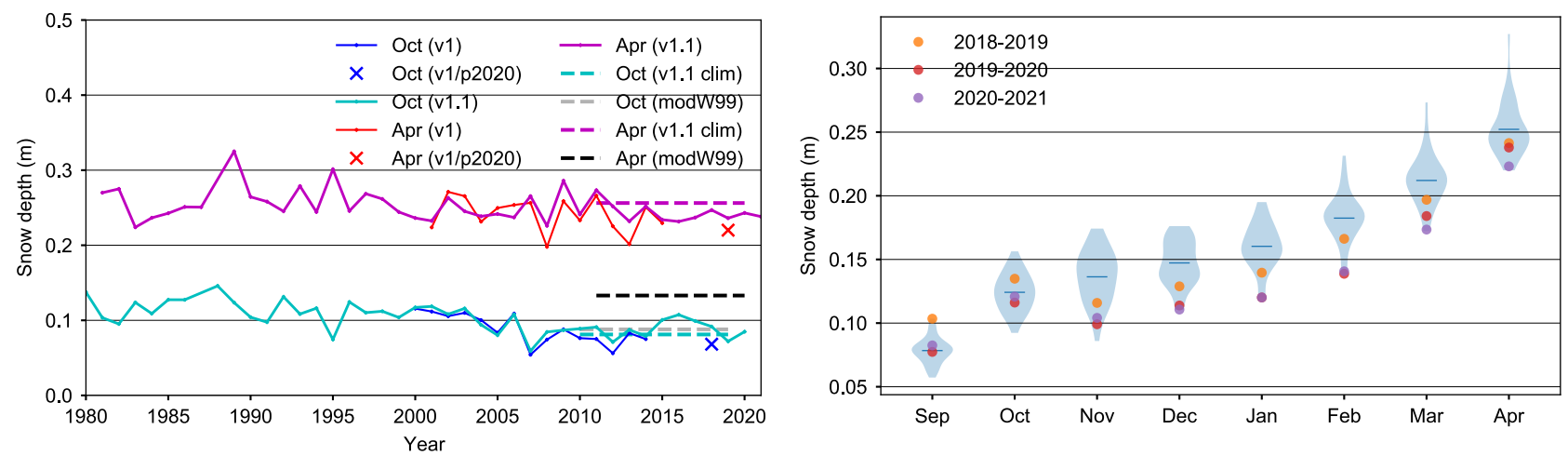

840 Figure 3: (left) Mean Arctic snow depths in October (Oct) and April (Apr) from NESOSIM v1.0 and v1.1 within an Inner Arctic Ocean domain (Figure S3). Snow depths are also masked where concentration (from passive microwave) is less than 50\%. The cross markers show the extended NESOSIM v1.0 results used in (Petty et al., 2020). The dashed colored horizontal lines show the NESOSIMv1.1 climatology (October 2010-2020 and April 2011-2021 means), while the dashed grey and black lines show the modified Warren climatology in October and April respectively. (right) violin plots showing interannual distributions of monthly mean snow depths from

845 NESOSIM v1.1 within an Inner Arctic Ocean domain from 1980-2021, colored markers indicate mean monthly snow depths for recent (ICESat-2) years. 
https://doi.org/10.5194/tc-2022-39

Preprint. Discussion started: 16 February 2022

(c) Author(s) 2022. CC BY 4.0 License.

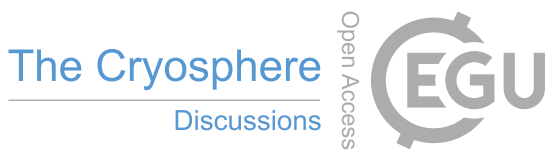
(c) (i)
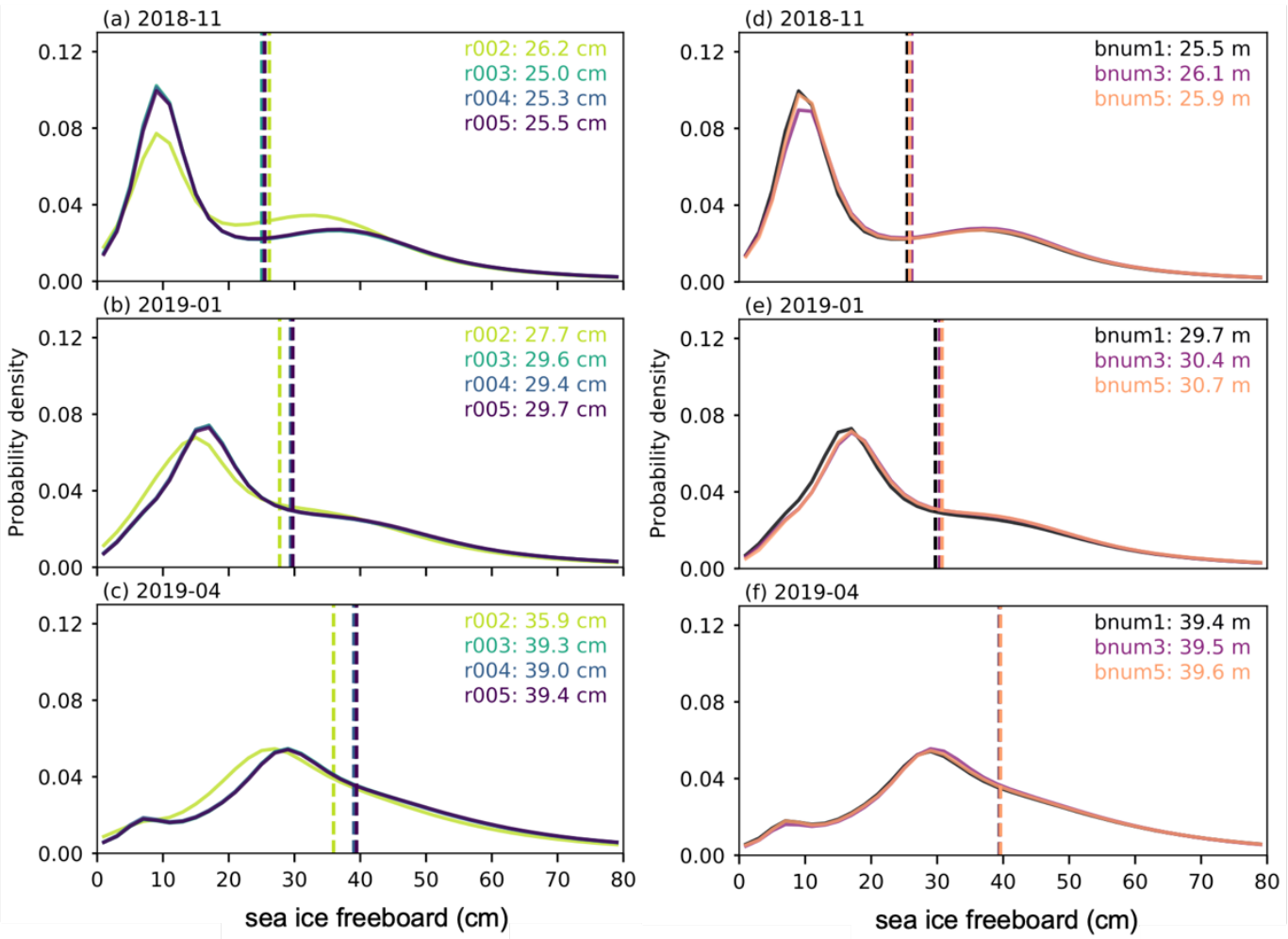

850 Figure 4: Probability distributions of ATL10 freeboard for (left column) Release 002 (rel002) to Release 005 (rel005) using strong beam \#1 in November 2018, (top) January 2019 (middle) and April 2019 (bottom), and (right column) strong beam \#1 $\# 3$ and \#5 for Release 005 data. 
https://doi.org/10.5194/tc-2022-39

Preprint. Discussion started: 16 February 2022

(c) Author(s) 2022. CC BY 4.0 License.

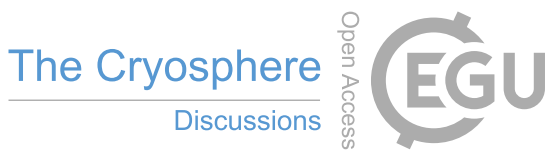
(c) (1)
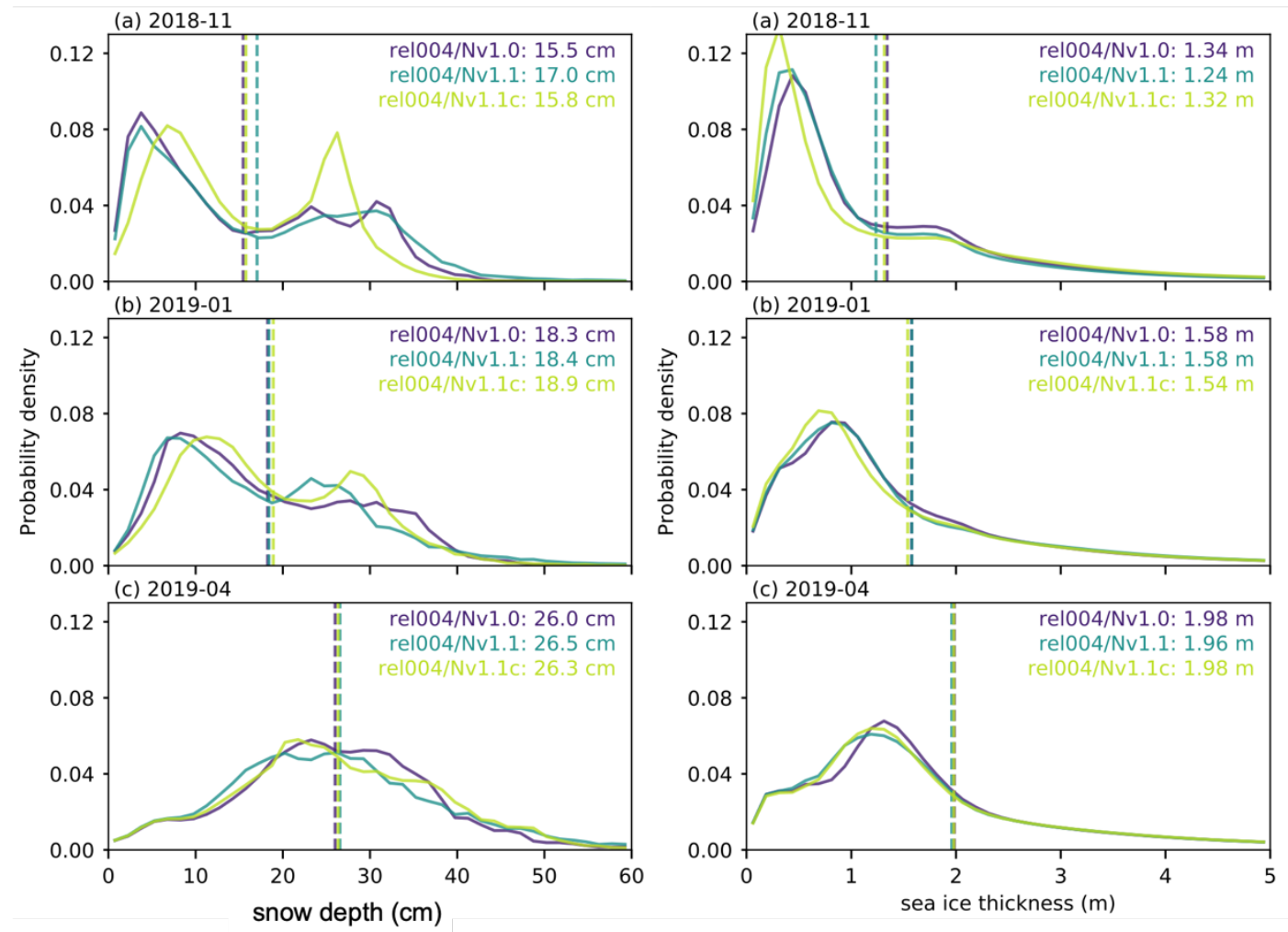

855 Figure 5: Probability distributions of (left column) redistributed snow depth and (right column) sea ice thickness, in November 2018, (top) January 2019 (middle) and April 2019 (bottom) using rel004 data from strong beam 1 within an Inner Arctic Ocean domain for runs using snow depth/density from NESOSIM v1.0 (Nv1.0), v1.1 (Nv1.1) and the v1.1 climatology (Nv1.1clim). 
https://doi.org/10.5194/tc-2022-39

Preprint. Discussion started: 16 February 2022

(c) Author(s) 2022. CC BY 4.0 License.
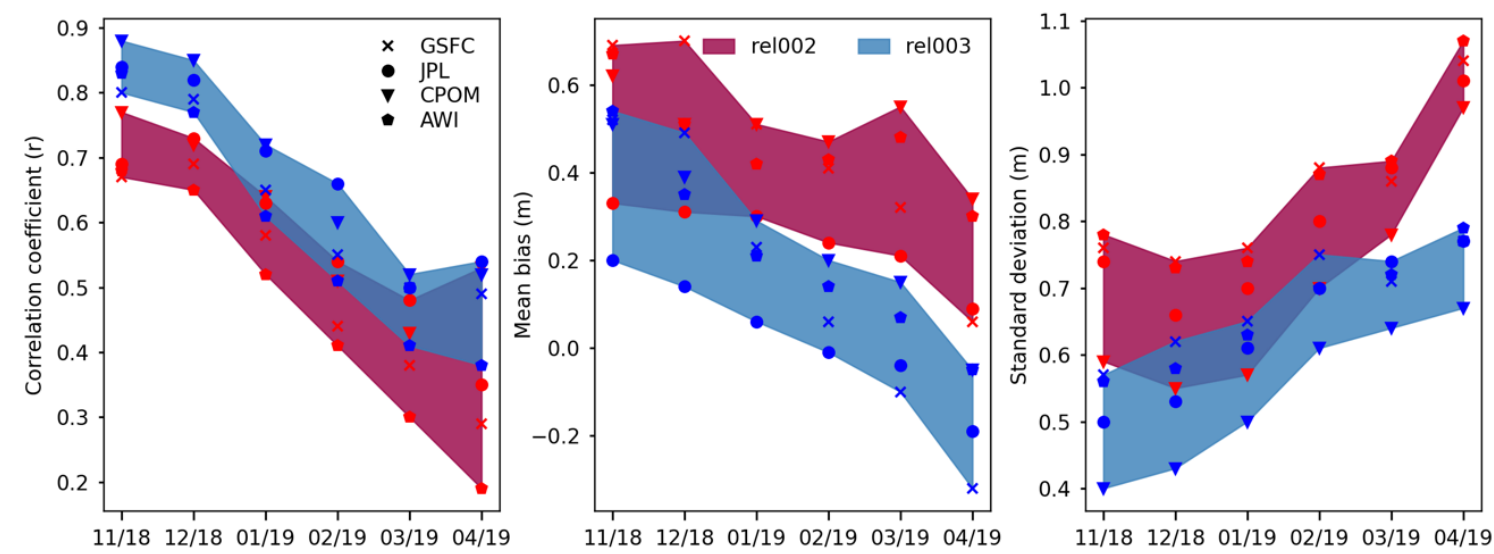

Figure 6: Comparison statistics of monthly gridded CryoSat-2 thickness for the four different CryoSat-2 products (GSFC, 865 JPL, CPOM, AWI) with gridded monthly ICESat-2 sea ice thickness using the same input assumptions (e.g., modified Warren climatology snow). Data are within an Inner Arctic Ocean domain for thicknesses $>0.25 \mathrm{~m}$. 
https://doi.org/10.5194/tc-2022-39

Preprint. Discussion started: 16 February 2022

(c) Author(s) 2022. CC BY 4.0 License.
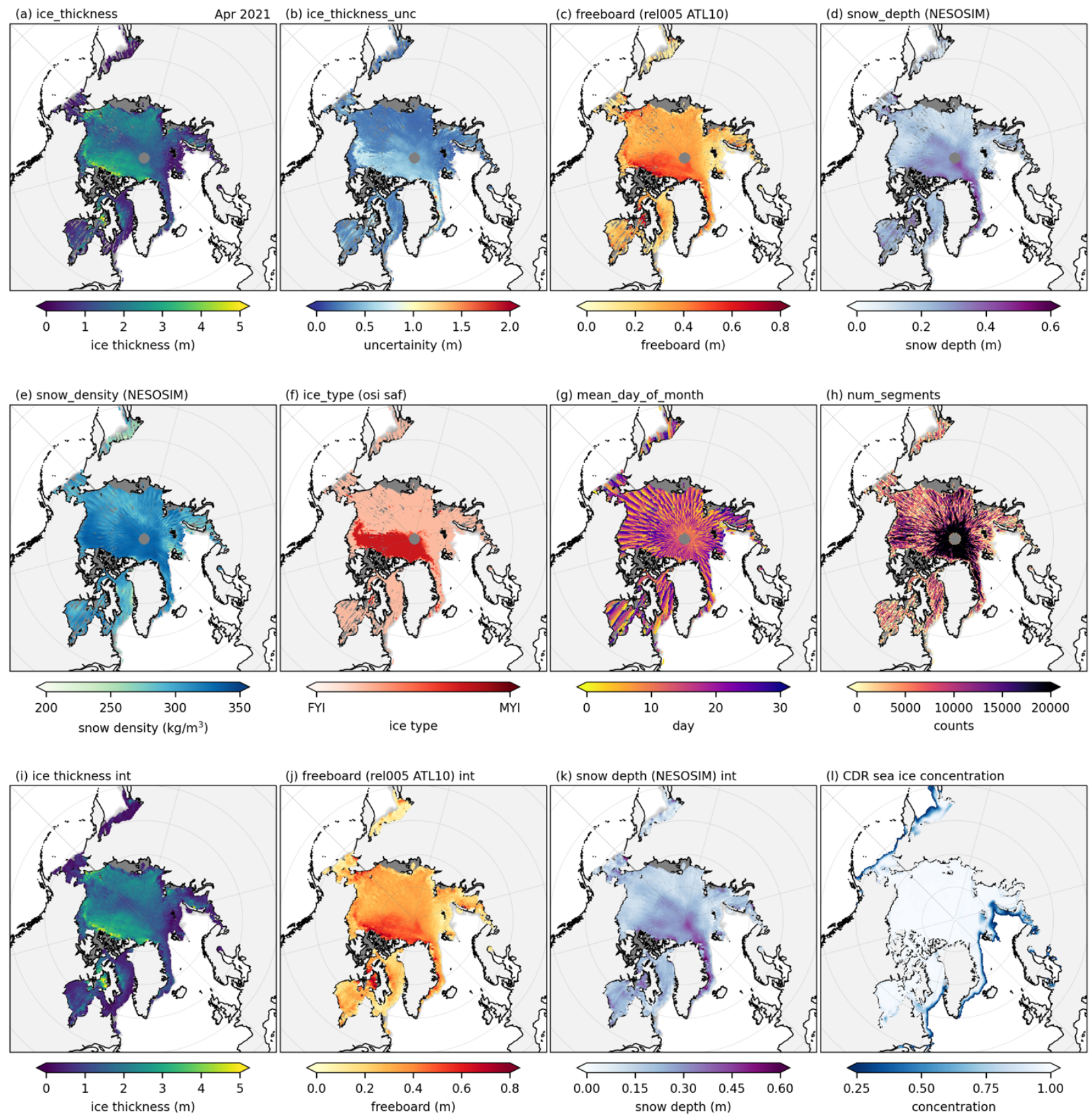

Figure 7: Example monthly gridded sea ice thickness dataset (IS2SITMOGR4, version 2) for April 2021. Data uses rel005

870 ATL10 freeboard and NESOSIM v1.1 across all three strong beams. The background gray shading in panels a to $\mathrm{k}$ is the CDR sea ice concentration shown in panel i. 

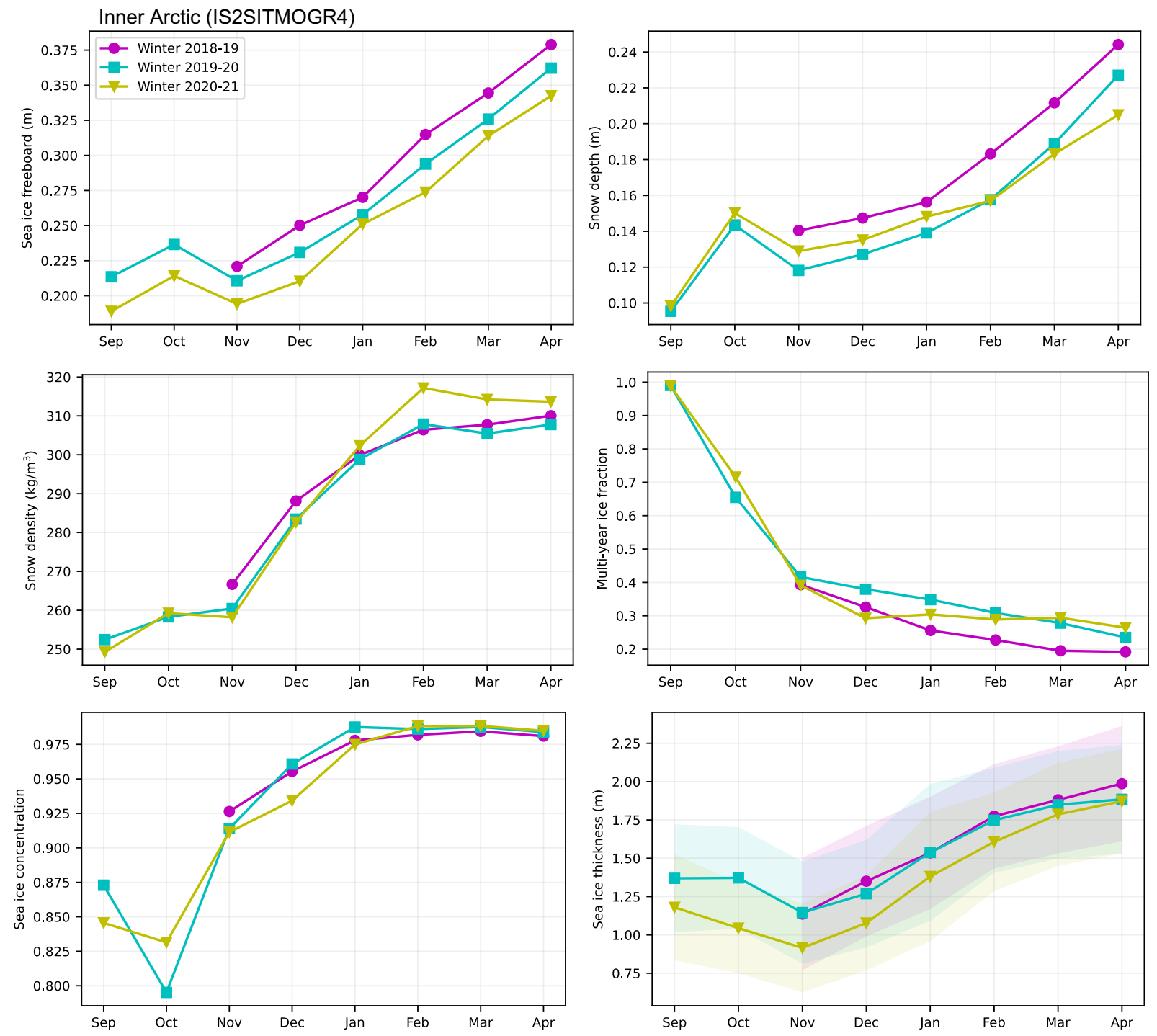

875 Figure 8: Time series of monthly mean ICESat-2 Inner Arctic Ocean sea ice freeboard (top left), redistributed NESOSIM v1.1 snow depth (top right), NESOSIM v1.1 snow density (middle left), OSI SAF multi-year ice fraction (middle right), CDR sea ice concentration (bottom left) and resultant sea ice thickness (bottom right) for the 2018/2019, 2019/2020 2020/2021 winters. Monthly means are generated using monthly gridded ICESat-2 thickness estimates (IS2SITMOGR4 v2, shown in Figure 7), masked outside of an Inner Arctic Ocean domain (see Figure S3). The shading in the lower right panel represents the mean systematic thickness uncertainty (see Figure $7 \mathrm{~b}$ for an example monthly ice thickness uncertainty field). 
https://doi.org/10.5194/tc-2022-39

Preprint. Discussion started: 16 February 2022

(c) Author(s) 2022. CC BY 4.0 License.
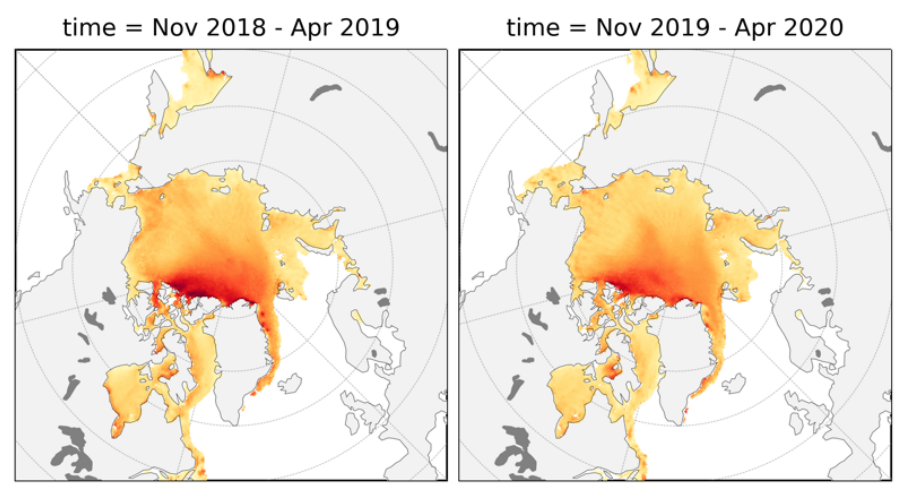

time $=$ Nov $2020-$ Apr 2021
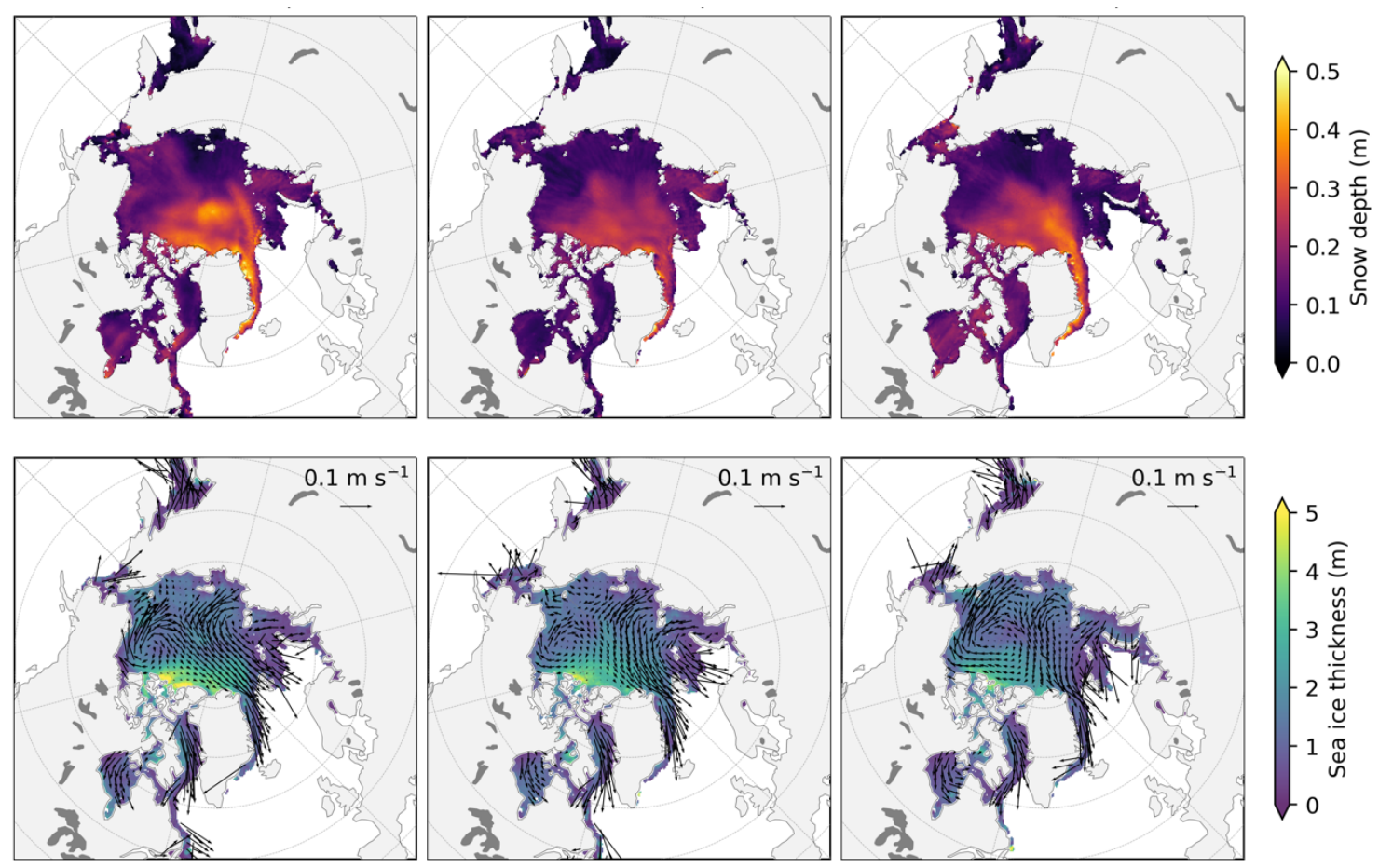

Figure 9: Winter (November to April) mean ICESat-2 freeboard (top) redistributed NESOSIM v1.1 snow depth (middle) and resultant sea ice thickness (bottom row) for the 2018-2019 (left column) 2019-2020 (middle column) and 2020-2021 (right column) winters based on the monthly gridded IS2SITMOGR4 v2 data (using the interpolated/smoothed variables for each variable). The thickness data are overlaid with winter mean OSI SAF drift vectors. 
https://doi.org/10.5194/tc-2022-39

Preprint. Discussion started: 16 February 2022

(c) Author(s) 2022. CC BY 4.0 License.
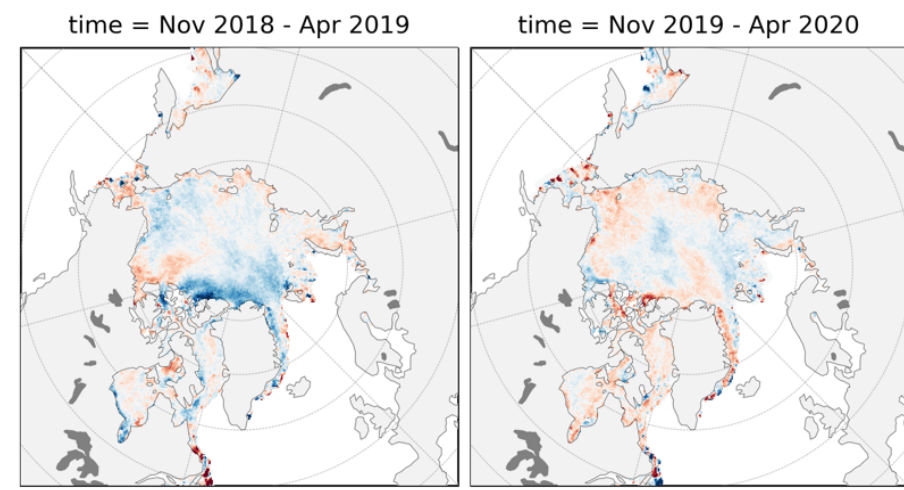

time $=$ Nov $2020-$ Apr 2021
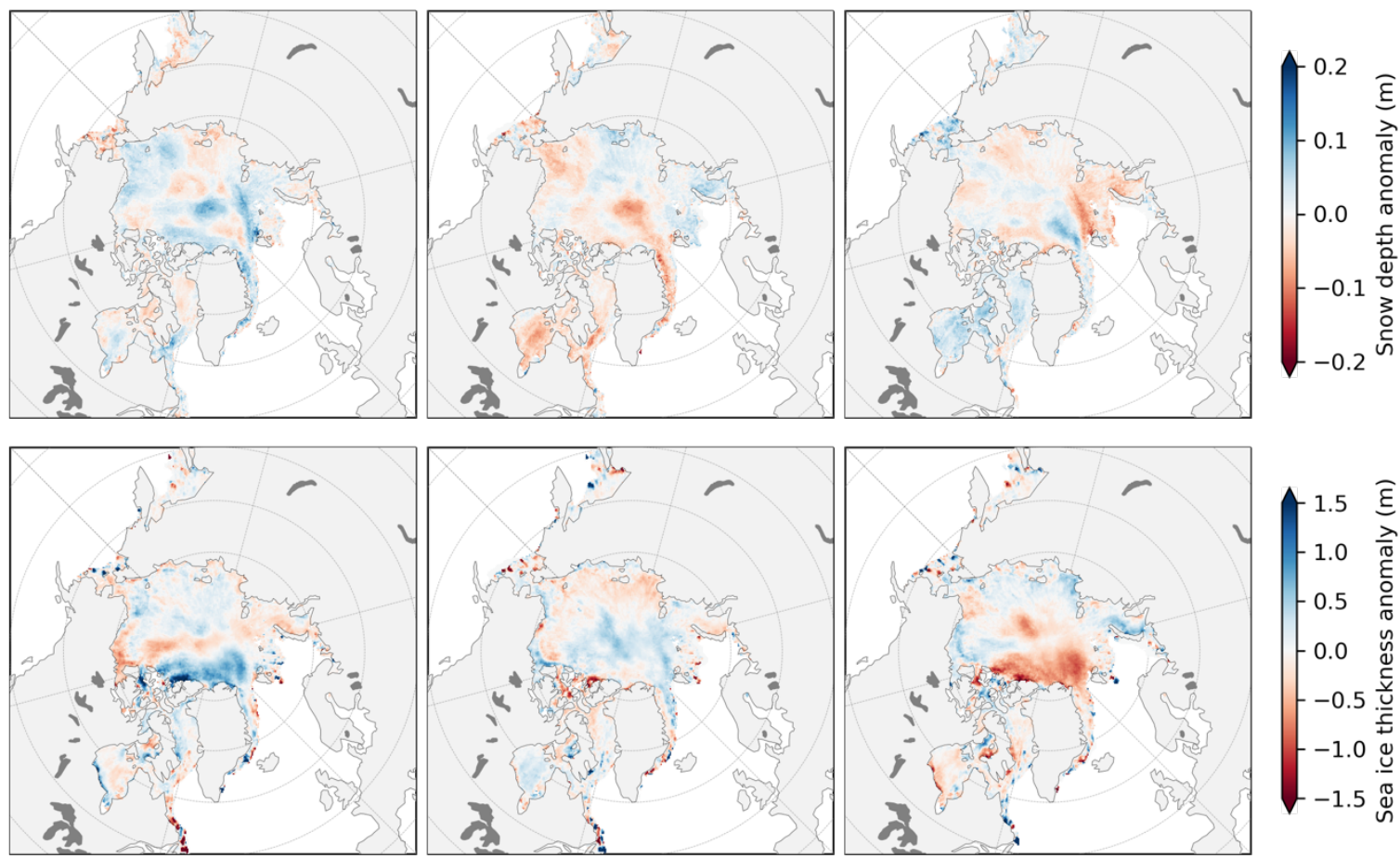

Figure 10: As in Figure 9 but showing the anomalies relative to the 2018-2021 winter means for the 2018-2019 (left column) 2019-2020 (middle column) and 2020-2021 (right column) winters. 
https://doi.org/10.5194/tc-2022-39

Preprint. Discussion started: 16 February 2022

(c) Author(s) 2022. CC BY 4.0 License.

(c) (i)

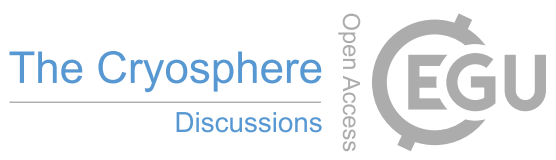

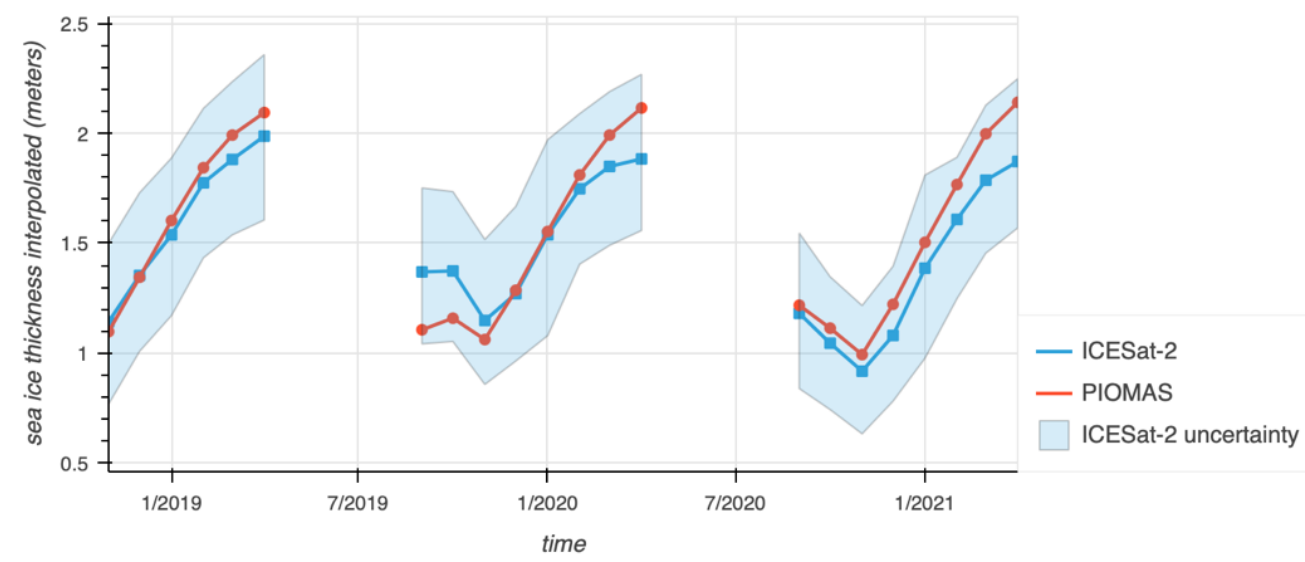

Figure 11: Comparisons of our monthly mean gridded ICESat-2-derived thickness estimates (IS2SITMOGR4, v002) against thickness estimates from PIOMAS. Data limited to $>90 \%$ sea ice concentration within our Inner Arctic domain where both 900 datasets provided positive $(>1 \mathrm{~cm})$ thicknesses 
https://doi.org/10.5194/tc-2022-39

Preprint. Discussion started: 16 February 2022

(c) Author(s) 2022. CC BY 4.0 License.

\section{(c) (1)}
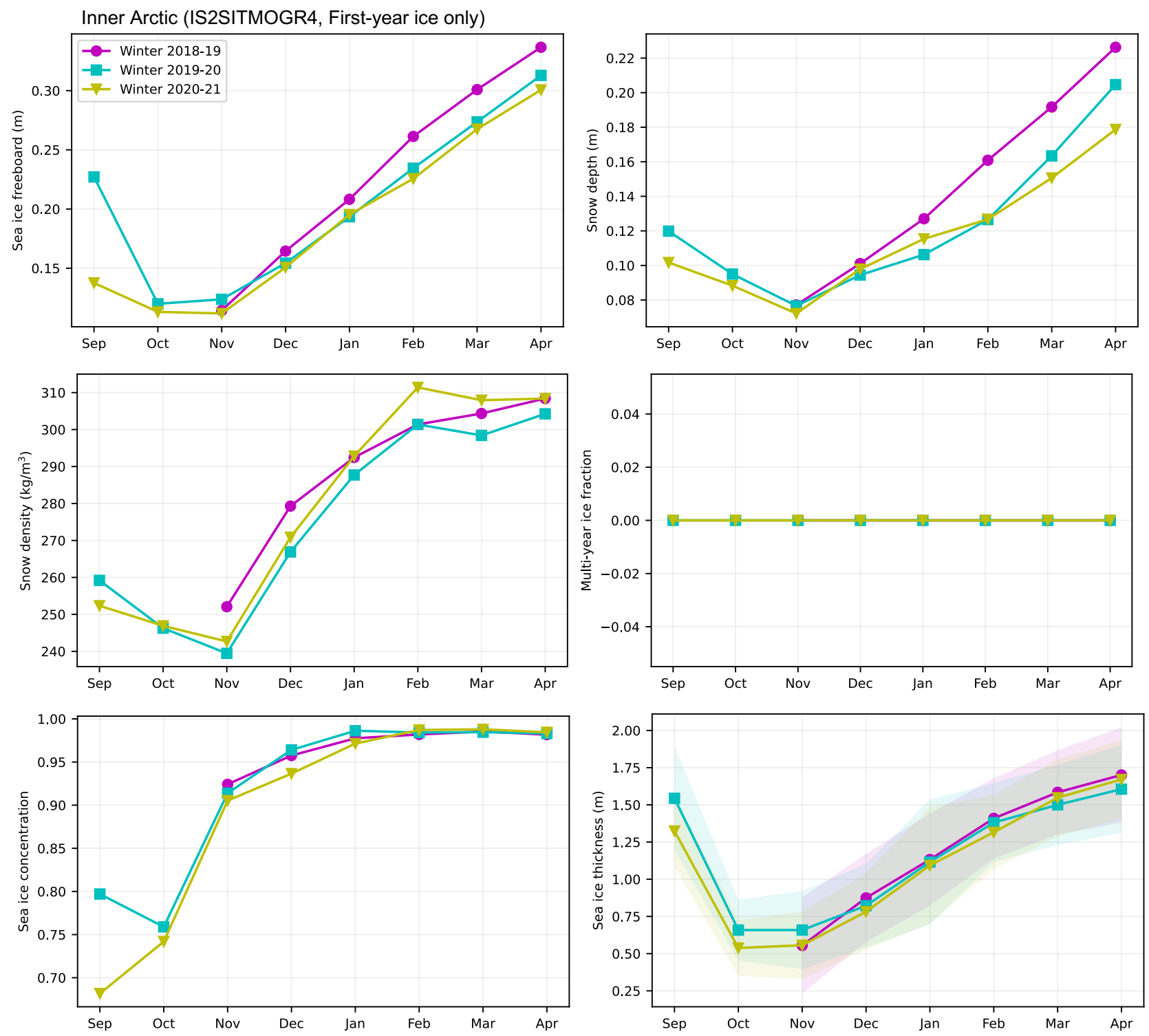

905

Figure 12: As in Figure 8 but for monthly means of grid-cells identified as first-year ice (FYI) only. 
https://doi.org/10.5194/tc-2022-39

Preprint. Discussion started: 16 February 2022

(c) Author(s) 2022. CC BY 4.0 License.

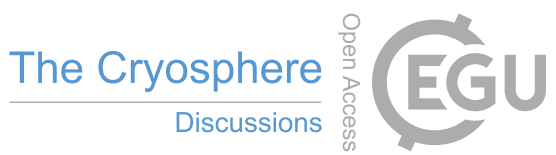
(c) (i)
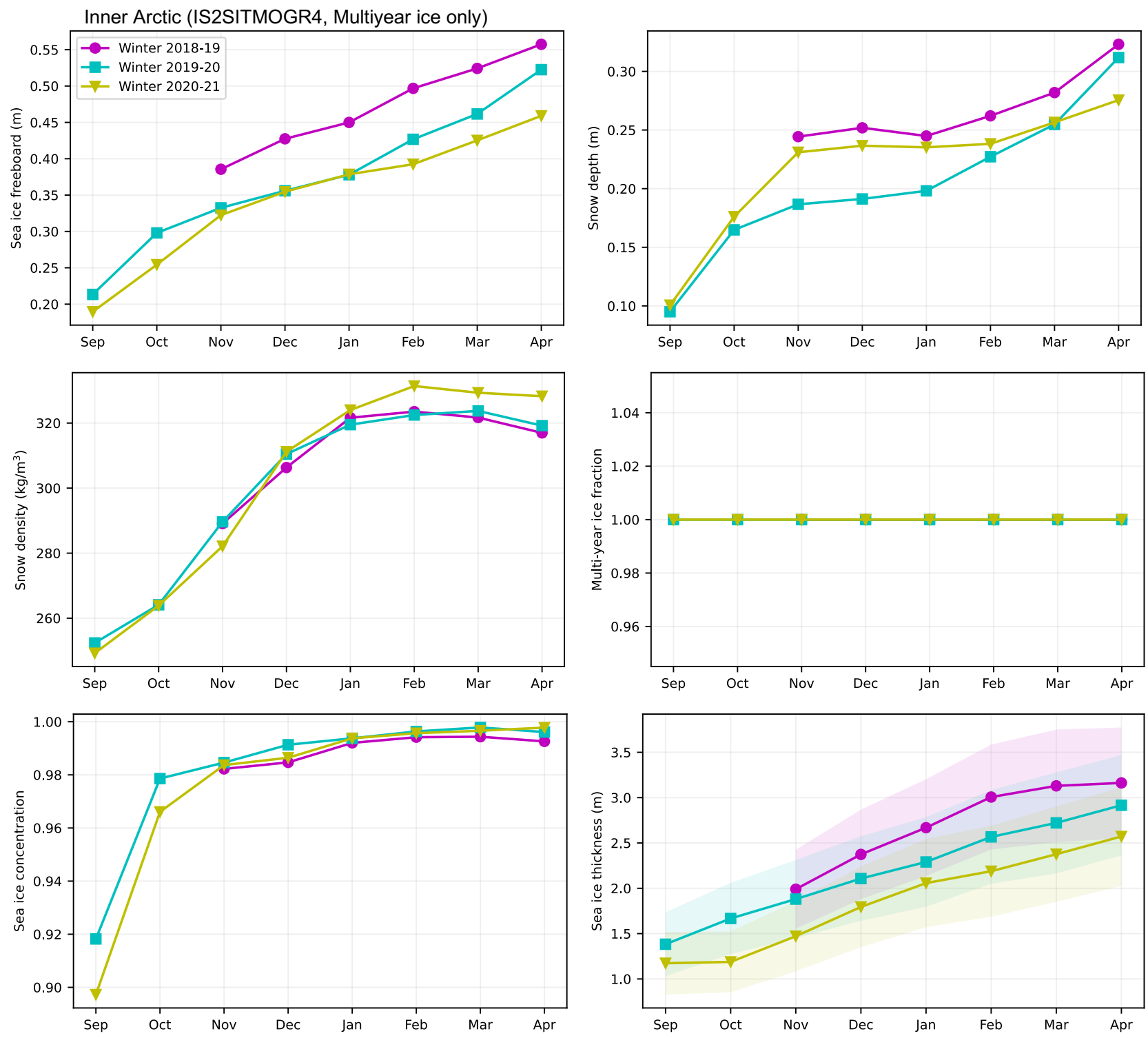

910 Figure 13: As in Figure 8 but for monthly means of grid-cells identified as multiyear ice (MYI) only. 
https://doi.org/10.5194/tc-2022-39

Preprint. Discussion started: 16 February 2022

(c) Author(s) 2022. CC BY 4.0 License.

(c) (i)
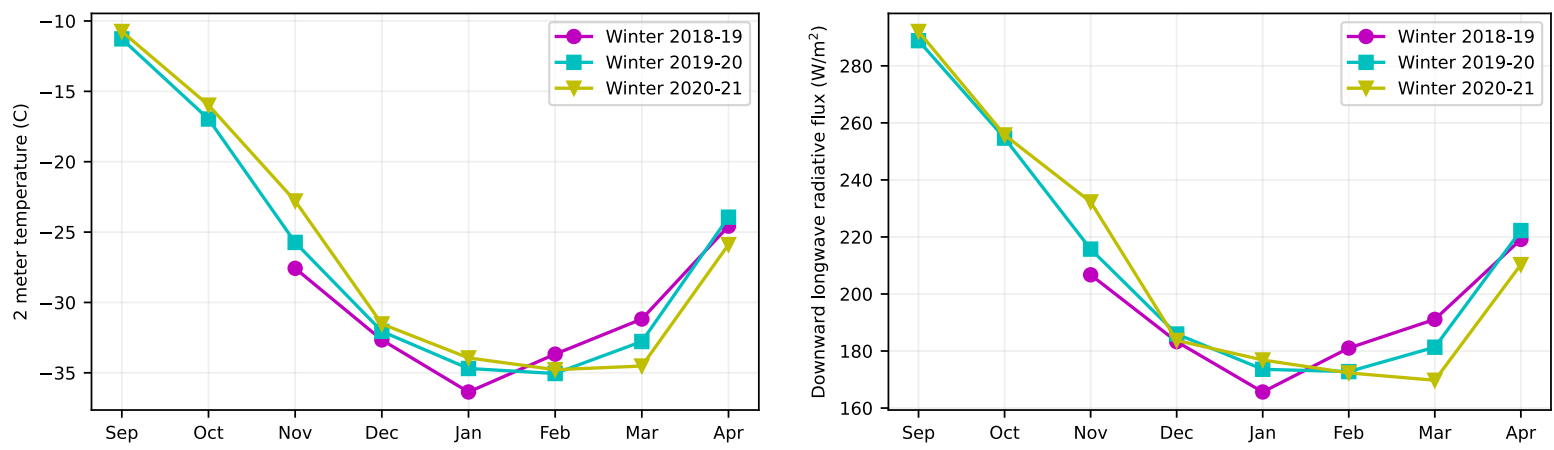

Figure 14: Time series of monthly mean $2 \mathrm{~m}$ temperature and downwelling longwave radiation from ERA5 within our Inner 915 Arctic Ocean region. 